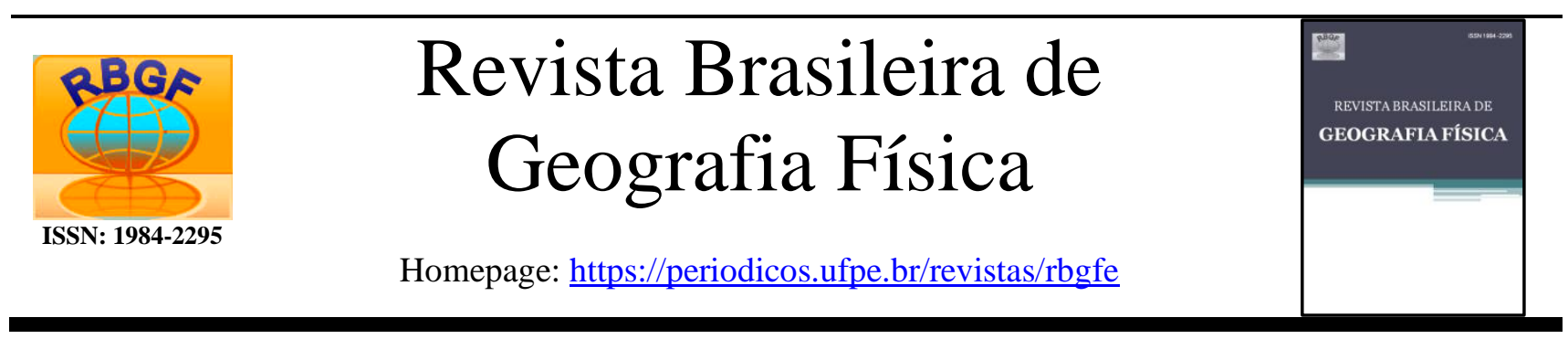

\title{
Paisagem rural da microrregião de Tomé-Açu sob a ótica bertrandiana
}

\author{
Leonardo Sousa dos Santos ${ }^{1}$ João Santos Nahum², Cleison Bastos dos Santos³, Orleno Marques da Silva Júnior ${ }^{4}$
}

\begin{abstract}
${ }^{1}$ Dr. em Geografia, Universidade Federal do Pará, Rua Barão de Igarapé Miri, 66075-045, Bairro Guamá, Belém do Pará, Brasil. (91) 98194-3148. leonardodrgeo@gmail.com (autor correspondente). ${ }^{2}$ professor Dr. em Geografia, Faculdade de Geografia e Cartografia e do Programa de PósGraduação em Geografia da Universidade Federal do Pará. Rua Augusto Corrêa, 66010-150, Belém do Pará, Brasil (91) 9267-5802. prof.joaonahum@gmail.com. ${ }^{3}$ Doutorando do Programa de Pós-Graduação em Geografia da Universidade Federal do Pará. Docente de Geografia da rede pública de ensino do Pará. Rua Lauro Sodré, 869, Bairro Centro, CEP: 68450-000, Moju, Pará. (91) 9149-8573. cleisongeo@ gmail.com. ${ }^{4}$ Dr. em Planejamento Energético, Instituto Alberto Luiz Coimbra de Pós-graduação e Pesquisa de Engenharia, Instituto de Pesquisa Científicas e Tecnológicas do Estado do Amapá. Rod. Juscelino Kubitschek, KM-10 - Fazendinha, CEP 68903-419 Macapá-Amapá. (96) 9170-5653. orlenomarques@yahoo.com.br.
\end{abstract}

Artigo recebido em 23/07/2019 e aceito em 16/12/2019

\section{RESUMO}

A formação da paisagem da Microrregião de Tomé-Açu (MRGTA) caminha pari passu com a reorganização e a configuração espacial desse território, agrupando intencionalidades sociais, que introduzem nos lugares onde aportam novas temporalidades e espacialidades segundo as lógicas dos mercados mundiais. As estradas, a exploração agropecuária e a expansão urbana são algumas das perturbações significativas nas Unidades de Paisagens (UPs) rurais dessa microrregião. O desafio deste trabalho foi ler e interpretar os Mosaicos de Unidades Homogêneas (MUH) através do sistema hierarquizado tripolar bertrandiano GTP (Geossistema-Território-Paisagem), das unidades superiores e inferiores, destacando a complexidade da paisagem rural. Utilizou-se de bases secundárias oriundas de instituições do Governo Federal para representação cartográfica das MUH. Posteriormente, organizou-se um Banco de Dados Geográficos através do Sistema de Informação Geográfica (SIG) QGis 2.18. Com os resultados, evidencia-se que alguns MUH se encontram bem diferentes dos tempos passados, representando uma pluralidade de formas e estruturas de ocupações, principalmente quanto à reprodução do capital, viabilizado e difundido pela ação estatal/empresarial, em especial da paisagem monótona da monocultura do dendê, que tem um arranjo único que causa impacto sociocultural no conjunto geográfico estudado. Do ponto de vista bertrandiano, revela-se que a paisagem da MRGTA possui um conjunto de formas heterogêneas (naturais e artificiais) que possibilitam interpretações particulares de vários tempos, escritos uns sobre os outros, e com idades e heranças de diferentes momentos. Por fim, constata-se que a paisagem da MRGTA possui uma complexidade, e a metodologia aplicada possibilitou ler as marcas e matrizes na paisagem, deixadas no tempo e no espaço dessa microrregião do agronegócio.

Palavras-chave: bertrand, gtp (geossistema-território-paisagem), paisagem rural.

\section{Rural landscape of Tomé-Açu micro region under georges bertrand's perspective}

\begin{abstract}
A B S T R A C T
The formation of the Tomé-Açu Micro region Landscape (MRGTA), Northern Brazil, goes hand in hand with the reorganization and spatial configuration of this territory, encompassing social intentionalities that introduce new temporalities and spatialities according to the logic of global markets. Roads, agricultural exploitation and urban sprawl are some of the significant disorders for the rural landscape units (UPs) in this micro region. The challenge of this research was to read and interpret the Mosaics of Homogeneous Units (MUH) through Georges Bertrand's tripolar hierarchical system GTP (Geosystem-Territory-Landscape), of upper and lower units, which highlights the complexity of the rural landscape. This research used secondary bases from Federal Government institutions for cartographic representation of the Mosaics of Homogeneous Units. Then, a Geographic Database was organized through the Geographic Information System (GIS) QGis 2.18. The results of the research indicate that some MUH are quite different from the past, representing a plurality of forms and structures of occupancies, especially regarding the reproduction of capital, made possible and disseminated by state and business actions, especially the monotonous landscape of palm oil monoculture, which has a unique conformation that causes sociocultural impact on the studied geographical object. From Bertrand's point of view, it is observed that the landscape of MRGTA has a set of heterogeneous forms (natural and artificial) that enable particular
\end{abstract}


interpretations from different times, written about each other, and with ages and inheritances of different times. Finally, it is understood that the MRGTA landscape has a complexity, and the applied methodology made it possible to read the marks and matrices in the landscape, left in time and space of this agribusiness micro region.

Keywords: bertrand, gtp (geosystem-territory-landscape), rural landscape.

\section{Introdução}

As discussões sobre paisagem é um tema de interesse científico, e que recebeu mais atenção na modernidade, desde o século XIX vem construindo seu referencial como ciência (Schier, 2003, Verdum et al., 2012). De acordo com De Britto e Ferreira (2011), a evolução das diferentes abordagens filosóficas sobre a paisagem congrega conceitos ora de forma estática, ora dinâmica, ora de caráter abstrato, ora como produto territorial das ações entre o capital e o trabalho, ora de caráter mais holístico (Suertegaray e Guasselli, 2004).

Os pensadores por meio de viagens, observações, descrições, comparações, valorizações e conclusões contribuíram com distintos referenciais, concepções e conceitos de paisagem, de acordo com sua trajetória temporal e espacial. O certo é que as abordagens para interpretação da paisagem foram ganhando postulados e formulações que garantiram níveis de observações e diferenciações da complexidade do espaço geográfico e suas transformações (Puntel, 2012).

Neste contexto, o destaque é para o trabalho da paisagem de forma integrada, por meio da combinação de elementos físicos, biológicos e antrópicos, proposta do Bertrand em 1971 e difundido no Brasil pela professora Olga Cruz (Pissinati e Archela, 2009).

De acordo com Pissinati e Archela (2009), o trabalho de Bertrand é uma análise das Unidades de Paisagem (UPs), relativamente estáveis, por meio de tipologias dinâmicas e hierarquizadas em unidades superiores (zona, domínio e região) e unidades inferiores (geossistema, geofácies e geótopo), em escalas que vão de alguns quilômetros quadrados até centenas de quilômetros quadrados.

A interpretação da paisagem de Georges Bertrand é fundamentada por uma classificação de elementos da paisagem que estão interrelacionados e que buscam retratar uma dinâmica natural instável que reagem com as atividades humanas (Ferreira et al., 2001; Pissinati e Archela, 2009; Souza, 2009).

Ou seja, Bertrand contrapõe-se à análise da paisagem compartimentada, trazendo à luz uma metodologia capaz de lidar com parte da complexidade indissociável da paisagem que está em perpétua evolução (Pissinati e Archela, 2009).
O desafio da análise da paisagem, sob a ótica Bertrandiana, é não ler a complexidade existente no dinamismo das paisagens apenas pelas aparências das coisas, como um cenário ou vitrine. Assim, Bertrand considera a paisagem como uma entidade global, composta por sociedade e natureza, interpretada por meio de categoria denominada de geossistema ou sistema GTP (Geossistema, Território e Paisagem) (Bertrand, 1971 apud Pissinati e Archela, 2009).

O GTP é uma metodologia de análise da paisagem que auxilia na superação da ruptura entre sociedade e natureza no espaço geográfico. $\mathrm{O}$ sistema tripolar é interativo possibilita a leitura da complexidade da paisagem expressa nas várias formas de relações construídas entre sociedade e ambiente (De Britto e Ferreira, 2011).

É necessário, porém, determinar uma porção do espaço geográfico para interpretação da paisagem, e que este seja composto de elementos físicos, biológicos e antrópicos que reajam dialeticamente, uns com os outros.

Neste sentido, o geógrafo francês define o meio rural como um espaço importante para interpretação da paisagem pelo método GTP, pois o meio rural é um espaço complexo, dinâmica e heterogênea que integra sistemas natural, cultural e social, com é reflexo da lógica local e mundial, a exemplo, da Microrregião de Tomé-Açu (MRGTA).

Assim o objetivo desse artigo é promover uma demonstração da potencialidade da análise integrada da paisagem em unidades superiores (zona, domínio e região) e unidades inferiores (geossistema, geofácies e geótopo) de um espaço rural que apresente particularidades da paisagem, abrangendo pontos importantes como delimitação, escala e relações da metodologia de estudo da paisagem sob a ótica Bertrandiana.

\section{Área de Estudo}

A Microrregião de Tomé-Açu (MRGTA) está localizada no nordeste do Estado do Pará, perfazendo uma área aproximada de 24.022,67 $\mathrm{km}^{2}$, entre as coordenadas $02^{\circ} 54^{\prime} 45^{\prime \prime}$ e $03^{\circ} 16^{\prime} 36^{\prime \prime}$ de latitude sul e de $47^{\circ} 55^{\prime} 38^{\prime \prime}$ e $48^{\circ} 26^{\prime} 44^{\prime \prime}$ de longitude. A MRGTA está limitada ao norte pelos Municípios de Concórdia do Pará e São Domingos do Capim, ao sul e leste pelo Município de Aurora 
do Pará e a oeste pelos Municípios de Tailândia e

Acará (Rodrigues et al., 2001) (Figura 1)

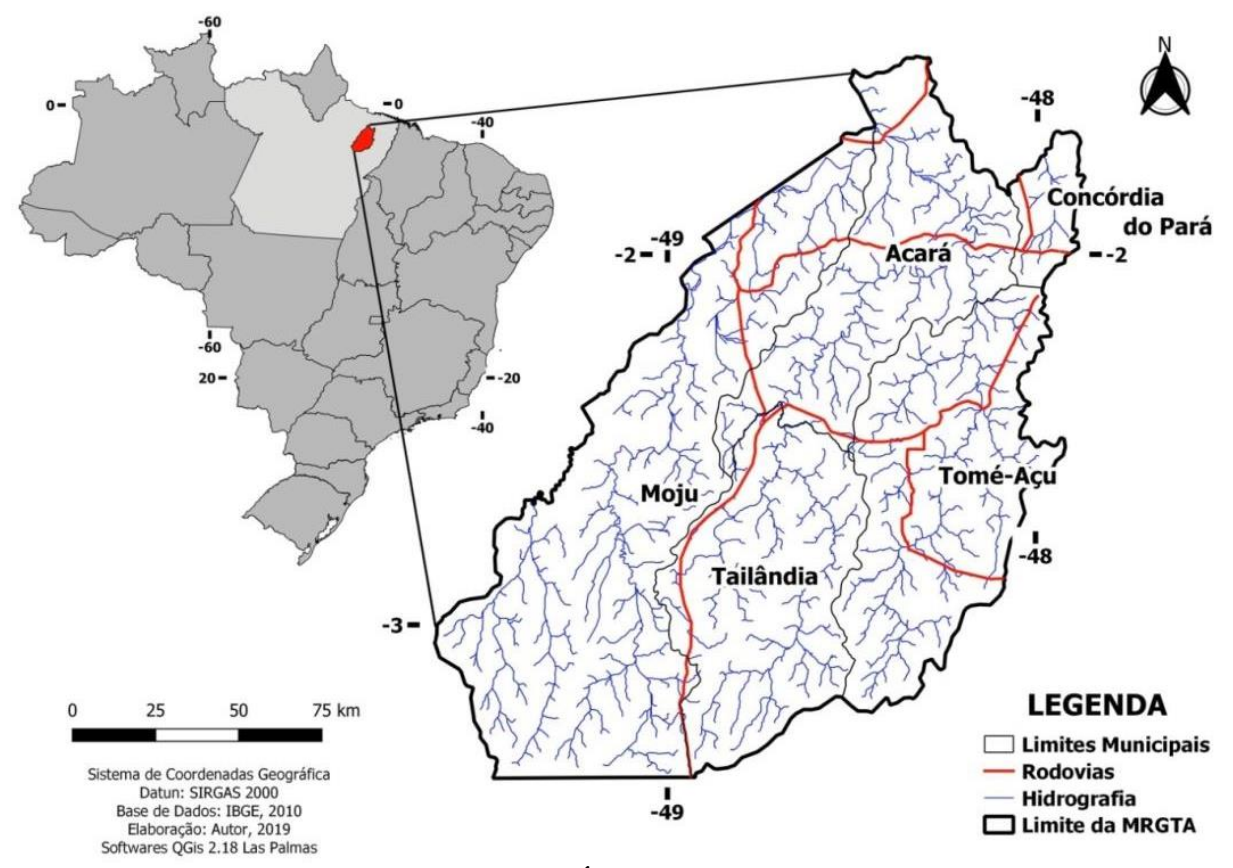

Figura 1. Área de estudo.

A população é de 325.988 habitantes (IBGE, 2016) e está dividida em cinco municípios: Acará, Concórdia do Pará, Moju, Tailândia e Tomé-Açu. O clima é mesotérmico e úmido, do tipo Ami de acordo com a classificação de Köppen, com temperatura média anual de $26^{\circ} \mathrm{C}$ e umidade relativa do ar em torno de $85 \%$. A média anual de precipitação é de $2.300 \mathrm{~mm}$ (Bolfe e Batistella, 2012).

\section{Metodologia e procedimentos operacionais}

A análise das unidades de paisagem da microrregião de Tomé-Açu foi realizada sob a ótica bertrandiana (1971), por meio de três pontos importantes, conforme definido por Georges Bertrand (1971), a saber:

$\mathrm{O}$ primeiro ponto refere-se à delimitação de Unidades Base (UBs) de estudo. Neste trabalho a UB é representada pelas SBH da MRGTA, pois se considera essa região como um espaço que mais se aproxima da realidade geografia geossistêmica proposta por Bertrand (1971). Cunha e Guerra (2011) destacam a importância da adoção das bacias hidrográfica como UB de interpretações dos fenômenos geográficos, pois está é considerada excelente unidades de gestão dos elementos naturais da paisagem.

$\mathrm{O}$ segundo ponto, visa facilitar a delimitação e as apreciações dos elementos das UPS, por meio de Mosaico de Unidades Homogêneas (MUH) em escala regional, destacando-se componentes relacionados às características físicas distintas de cada MUH de: morfologia, geologia, relevo e clima e mais as ações antrópicas, conforme preceitua Bertrand (1971).

Os MUH reduziram as fragmentações entre os elementos das UPs por meio de Zonas Homogêneas (ZH) ou componentes relativamente homogêneos das UPs da MRGTA, possibilitando a combinações e diálogos entre elementos naturais e antrópicos (Ferraro et al., 2012).

$\mathrm{O}$ terceiro ponto refere-se à identificação e compreensão da ação antrópica (marcas) na paisagem rural da MRGTA, em especial da realidade da expansão da dendeicultura, impulsionados pelos planos e políticas de incentivo do Estado, fechando a observação do "complexo territorial natural" e a dimensão da paisagem percebida, proposto por Bertrand.

$\mathrm{Na}$ perspectiva geossistêmica (Figura 2), analisou-se as estruturas e algumas transformações das UPs, resultante da interação entre potencial ecológico, exploração biológica e a ações antrópicas mais evidentes, tendo a região como escala de apreensão, permitindo analisar as repercussões de parte da organização e do funcionamento social e econômico sobre este território.

Como na prática o estudo de Unidades de Paisagens (UPs) requer informações cartográficas, utilizaram-se bases cartográficas secundárias de 
instituições reconhecidas pelo Governo Federal, tais como: limite da microrregião do Instituto Brasileiro de Geografia e Estatística (IBGE), limites das bacias hidrográficas, redes de drenagens e massa d'água da Agência Nacional de Águas (ANA), além de dados morfológicos, geológicos e de relevo (Miranda, 2005) do Serviço Geológico do Brasil (CPRM), dentre outros para representação cartográfica dos MUH.

Ainda nesta fase, organizou-se um Banco de Dados Geográficos (BDG) através do Sistema de Informação Geográfica (SIG) QGis 2.18, licenciado pela General Public License (GNU).

As representações cartográficas retratam a distribuição espacial dos MUH dos aspectos geológicos, geomorfológicos, pedológicos e uso e cobertura da terra que integram as relações físicas e biológicas da paisagem rural da MRGTA.

$\mathrm{Na}$ elaboração dos mapas foi utilizado mosaico de imagens do relevo do Brasil dos dados de Shuttle Radar Topography Mission (SRTM) com resolução espacial de 60 metros, disponibilizadas gratuitamente pela Embrapa Monitoramento por Satélite (Miranda, 2005).

$\mathrm{Na}$ construção do Modelo Digital de Terreno (MDE) empregado as cenas SA-22-Z-A, SA-22-Z-B, SA-22-Z-C, SA-22-Z-D, SA-22-X-D, SA-23-Y-A e SA-23-V-C, com articulação compatível com a escala 1: 250.000 (IBGE).

Para identificação da cultura do dendê manipulou-se imagens do sensor Landsat- 8 sensor Operational Land Imager (OLI) para os anos de 2018, com resolução espacial de 30 metros, obtidas gratuitamente do repositório público de dados do United States Geological Survey (USGS), divulgado através do EarthExplorer.

A composição colorida foi Falsa-Cor/5r4g-3b. Por fim, observou-se também na leitura da paisagem por meio do Uso e Cobertura da Terra (UCT), dividida em duas etapas.

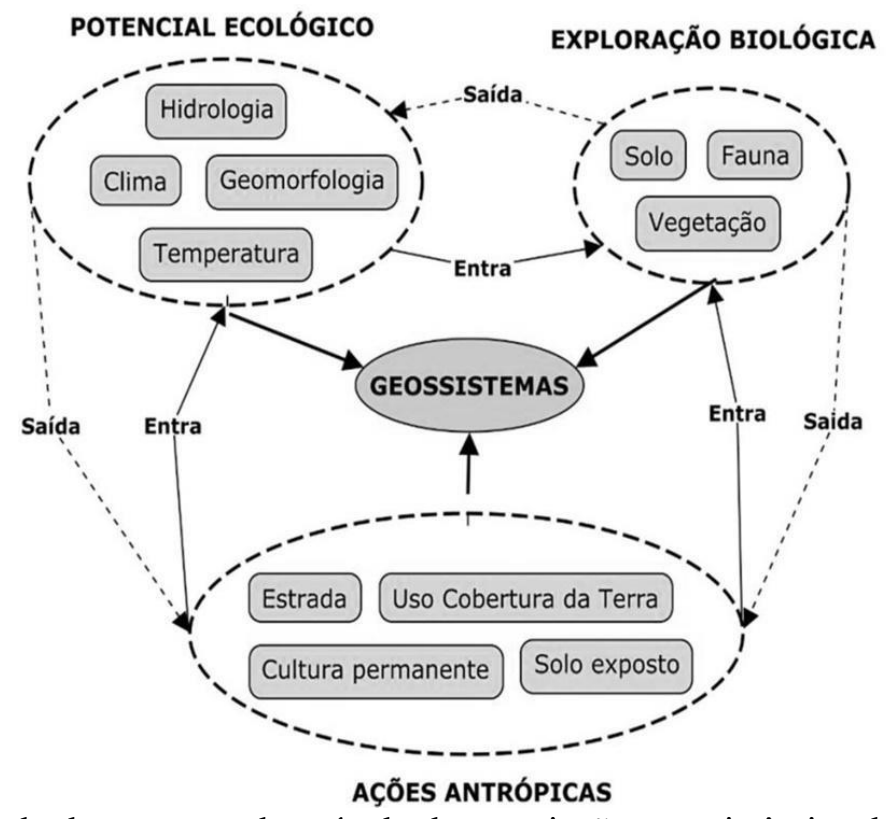

Figura 2. Adaptado do esquema do método de apreciação geossistêmica de Bertrand (1971).

Na classificação do MUH/UCT aplicou-se o algoritmo de classificação denominado de "Máxima-verossimilhança" (Maxver), que consiste em um método de segmentação de imagens orbitais supervisionada, com base em de pontos de controle coletados em trabalho de campo e validação sobre as informações dos dados do uso e cobertura da terra na Amazônia Legal do TerraClass 2014.

Por fim, definiram-se as Zonas Homogêneas (ZHs) com base no cruzamento das informações de cada mapa das MUH da paisagem, como a declividade, altimetria, relevo, solo, rede de drenagem, Uso e Cobertura da terra (UCT), estrutura e agricultura para interpretação geossistêmica em seis níveis, sendo três superiores (zona, domínio e região) e três inferiores
(Geossistema, geofácies e geótopo), propostos Bertrand (1971).

\section{Paisagens rurais da microrregião de Tomé-Açu sob a ótica bertrandiana}

O trabalho de Bertrand (1971) é uma análise das Unidades de Paisagem (UPs), relativamente estáveis, por meio de tipologias dinâmicas e hierarquizadas em unidades superiores (zona, domínio e região) e unidades inferiores (geossistema, geofácies e geótopo), em escalas que vai alguns quilômetros quadrados até centenas de quilômetros quadrados (Pissinati e Archela, 2009).

A interpretação da paisagem por Georges Bertrand é fundamentada por uma classificação de 
elementos que estão inter-relacionados e que buscam retratar uma dinâmica natural instável que reagem com as atividades humanas (Ferreira et al., 2001; Pissinati e Archela, 2009). Ou seja, Bertrand (1971) traz à luz uma metodologia capaz de lidar com parte da complexidade indissociável da paisagem que está em perpétua evolução (Pissinati e Archela, 2009).

A análise da paisagem, sob a ótica bertrandiana, implica em ler a complexidade existente no dinamismo das paisagens para além das aparências das coisas, como um cenário ou vitrine, mas considera as UPs como entidades globais, composta por sociedade e natureza, interpretada por meio de categoria denominada de geossistema ou sistema Geossistema, Território e Paisagem (GTP) (Bertrand, 1971 apud Pissinati; Archela, 2009).

O sistema GTP é uma sistematização de análise da paisagem que auxilia na superação da ruptura entre sociedade e natureza no espaço geográfico, por meio de eixos horizontal e vertical ou Zonas Homogêneas (ZHs).

O sistema tripolar é interativo e possibilita a leitura da complexidade da paisagem expressa nas várias formas de relações construídas entre sociedade e ambiente (De Britto e Ferreira, 2011). A tríade GTP, revela a totalidade das formas de criações, de reproduções e de transformações das estruturas das paisagens (Bertrand; Bertrand, 2007).

Contudo, é necessário determinar uma porção do espaço geográfico para interpretação das UPs, e que este seja composto de elementos físicos, biológicos e antrópicos que reajam dialeticamente, uns com os outros.

O geógrafo francês define o meio rural como um espaço importante para interpretação da paisagem pelo método GTP, porque é um espaço complexo, dinâmico e heterogêneo que integra sistema natural, cultural e social, e seu reflexo da lógica local e mundial.

Na prática, o estudo da paisagem rural sob a ótica bertrandiana (1971) requer representações cartográficas em escala de apreensão adequada a cada nível hierárquico de classificação da paisagem, podendo variar de centenas de quilômetros quadrados, passando por metros quadrados até centímetros quadrados.

Nessa proporcionalidade, Bertrand (1971) subdivide espaço em categorias espaciais, de componentes relativamente homogêneos nomeados de Mosaicos de Unidades Homogêneas (MUH), cujas estruturas e dinâmicas resultam das interações entre os potenciais ecológicos, biológicos e ação antrópicos.

Os Mosaicos de Unidades Homogêneas (MUH) materializam o conceito de escala de investigação do sistema tripolar bertrandiano por meio de eixo horizontal e vertical.

$\mathrm{Na}$ Figura 3, visualizam-se as UPs regionais sobre eixos perceptíveis do $\mathrm{MUH}$, tendo como escala de apreensão a paisagem regional, destacando as diferenciações espaciais dos elementos naturais subdivididos como unidade de análise de UPs que mais se aproximam da realidade geográfica e as quais são mais modificadas pelo homem ao longo da história.

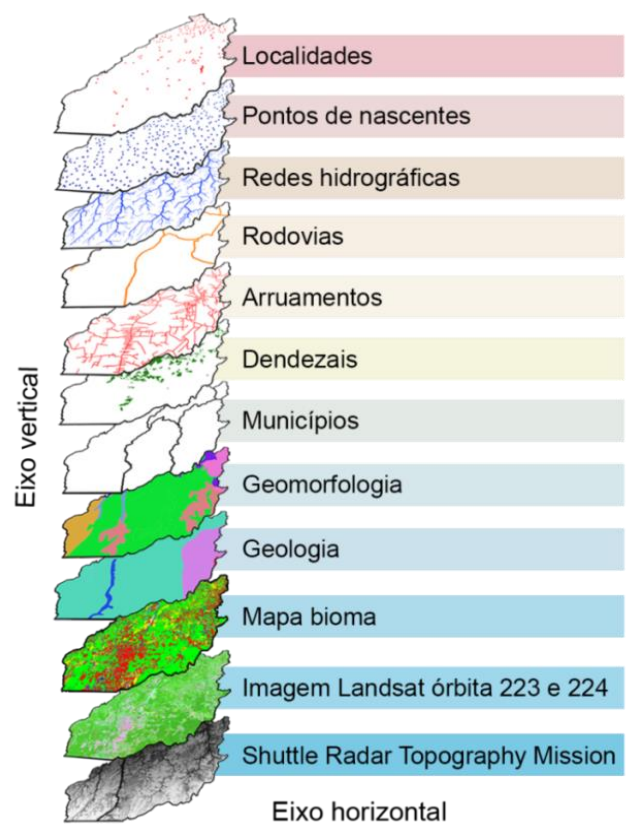

Figura 3. Mosaicos de Unidades Homogêneas (MUH). 
No eixo horizontal, acontece a leitura pela análise dos arranjos espaciais que integram as diferentes UPs. Já no eixo vertical é possível por meio de cortes e perfis transversais, destacar as partes que estão contidas no todo.

Os Mosaicos de Unidades Homogêneas (MUH) e suas extensões territoriais e limites identificáveis em eixos podem dar o mínimo de organização espacial de fenômenos corológicos sobre uma dada área que na maioria das vezes são construídas ou destruídas pela ação humana, sob a égide do grande capital.

Portanto, através dos eixos pode-se efetuar a leitura dos aspectos geológicos, geomorfológico, relevo, declividade, UCT, rede de hídricos e estradas que caracterizam as UPs (Martinelli e Pedrotti, 2011; Verdum et al., 2012;). As referências de eixos horizontal e vertical de UPs também são conhecidas como Zonas Homogêneas (ZHs) (Ferraro et al., 2012).

\section{Mosaicos de unidades homogêneas superiores (zona, domínio e região)}

O primeiro cenário de hierarquia de classificação dos Mosaicos de Unidades Homogêneas (MUH) bertrandiana é a "Zona", que coloca a microrregião de Tomé-Açu no planisfério da zona intertropical ao sul do trópico de capricórnio na América do sul setentrional, representado uma área de maior aquecimento solar da superfície terrestre.

A posição do MUH da Zona dessa microrregião é limitada ao norte e ao sul com os escudos cristalinos brasileiros e das guianas, correspondendo uma planície com imensas áreas de terras planas e baixas. Nesta zona, encontra-se a maior biodiversidade continental, compostas por plantas, animais e microrganismos diversos, alguns ainda nem descobertos (Ab'saber, 2003).

Ainda sob a ótica das unidades superiores destaca-se a MUH do "Domínio" da MRGTA, correspondendo o domínio da Amazônia panamericana de terras baixas de floresta equatorial, que repousa sobre a superfície do maciço cristalino que forma uma grande bacia sedimentar terciários de terreno argilo-arenosos, por onde corre o rio Amazonas que nasce no Peru e depois percorre o território brasileiro.

A última classificação do nível superior do MUH é a "Região natural" com mata fechada e densa, formadas por árvores imensas adaptadas a grande quantidade de água (higrófitas).

A floresta equatorial da Amazônia possui grupos de vegetais com folhas largas e grandes (latifoliadas) que se desenvolvem acima do solo de baixa fertilidade (Ab'saber, 2003).

De forma geral, na paisagem natural da hiléia amazônica é estão inseridas as matas de igapó, as matas de várzea e as matas de terra firme de baixa amplitude térmica e como alto regime pluviométrico, decorrentes das chuvas de convecção, as quais abastecem uma enorme rede de drenagem composta por igarapés e rios autóctones de águas brancas, negras ou claras (Vasconcelos, 2013).

\section{Mosaicos de unidades homogêneas inferiores (geossistema, geofácies e geótopo)}

Ainda sob a ótica de níveis hierárquicos, são definidos os Mosaicos de Unidades Homogêneas (MUH) das unidades inferiores denominados: geossistemas, caracterizados como unidades fisionômicas homogêneas, sendo um complexo geográfico; as geofácies que representa uma subdivisão destas unidades com seus aspectos fisionômicos e os geótopos, como sendo o último nível de escala espacial homogêneo proposto por Bertrand (1971).

No nível geossistêmico a vegetação é a representação que melhor síntese esse MUH da MRGTA, pois é o mosaico mais dominante dessa microrregião. Todavia, avançou-se em outras unidades espaciais de componentes relativamente homogêneos que testemunham as relações entre a natureza e a sociedade, como o uso de cobertura da terra, que se aproxima do conceito de paisagem global bertrandiana.

\section{Geossistema do Uso e Cobertura da Terra (UCT)}

No Mosaico de Unidades Homogêneas (MUH) do geossistema o uso e cobertura da terra da Microrregião de Tomé-Açu (MRGTA) que mais se destacam nessa microrregião é a floresta primária, a pastagem e o cultivo do dendezeiro, em razão de suas áreas territoriais.

O MUH de Floresta primária correspondendo a uma geofácie de mais de 14 mil $\mathrm{km}^{2}$ e que sofreu uma redução de mais $43 \%$ ao longo de 30 anos. A Pastagem é hoje na MRGTA uma geofácie com 4 mil km², a qual cresceu mais $45 \%$ em três décadas.

Os dendezal é uma MUH com mais de 2 mil $\mathrm{km}^{2}$ de geofácies. A partir da imagem do satélite Landsat 8/OLI de 2018, foi identificada a distribuição de 808 polígonos de cultivos de dendê, com área média de $2,91 \mathrm{~km}^{2}$, sendo a maior área 
com $153,35 \mathrm{~km}^{2}$ e a menor dendezal com 0,003 $\mathrm{km}^{2}$, totalizando $2.291,66 \mathrm{~km}^{2}$.

As áreas ditas "naturais" como a floresta possuem ocupação efetiva, com diferentes sucessões vegetais secundárias. No início, a vegetação original da MRGTA era composta na sua totalidade pela floresta ombrófila densa, pouco alterada, com espécie como mogno, cerejeira, imbuia, peroba, angelim, aroeira e a castanheira (Costa, 2012).

A cada ano a floresta foi convertida em vegetação secundária ou solo exposto, após o uso temporário da terra para exploração madeireira, pastagem, agricultura e hoje para agronegócio.

Ou seja, a geofácie de cobertura vegetal foi progressivamente suprimida para uso variado, sendo constantemente incorporada, na maioria das vezes de maneira inadequada, a produção agropastoril, expansão da malha urbana, dentre outros (Becker, 1995; Becker, 2009).

A derrubadas da mata, principalmente ao longo das rodovias, produziu algumas das primeiras marcas das transformações ocasionadas pela ação humana, deixando assim de existir a "naturalidade" da paisagem, por meio das primeiras fazendas de criação de gado bovino.

Para Cardoso (1977), as maiorias dos núcleos urbanos da MRGTA originaram-se de fazendas de gados, fazendo mistas com gados e lavoura de subsistência, com destaque da mandioca, milho, que são agriculturas anuais, praticadas sem qualquer técnica e cultivo.

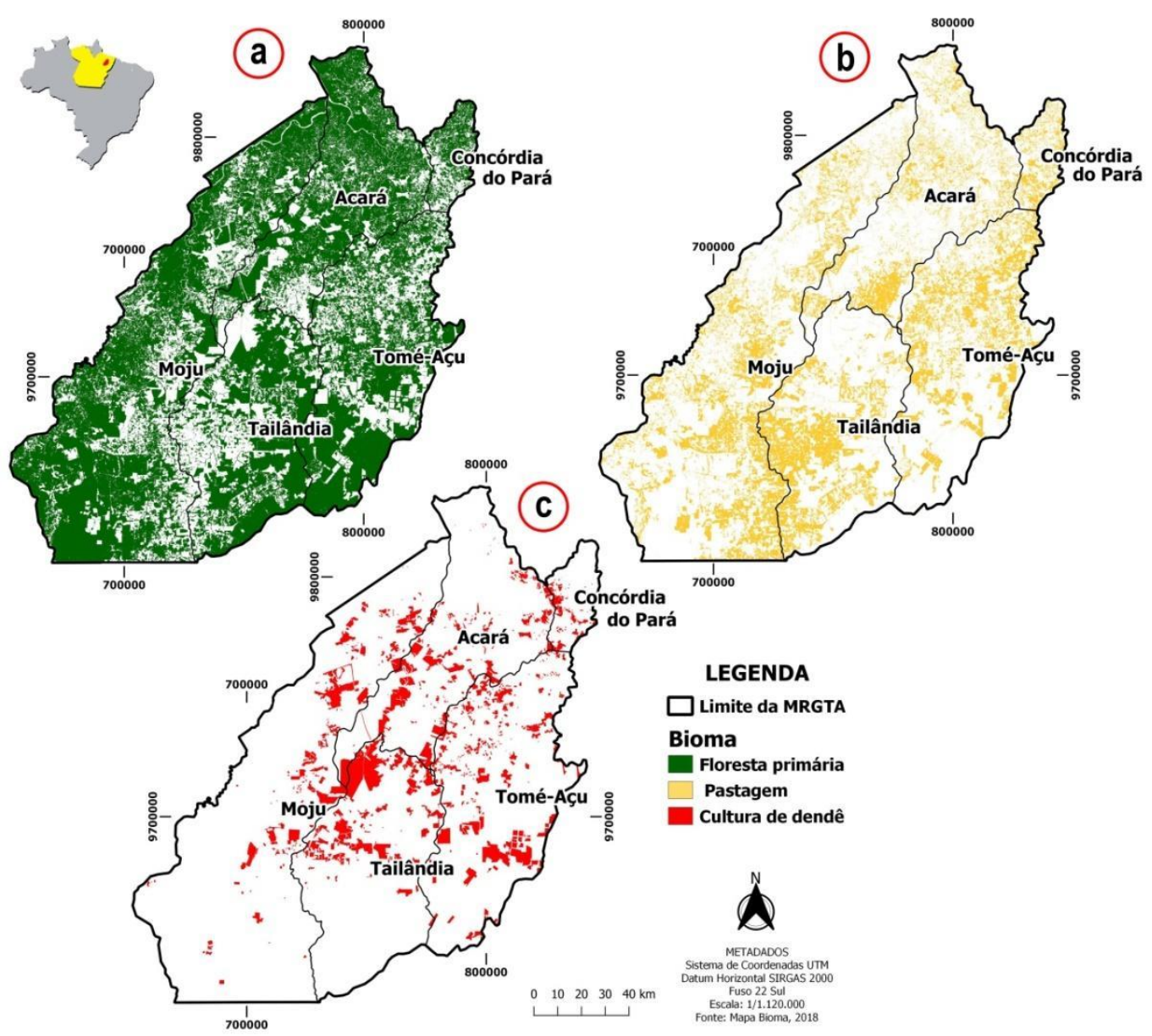

Figura 3. Principais geossistemas de UCT da paisagem da MRGTA.

$\mathrm{Na}$ Figura 4, visualizam-se os três geossistemas de UCT de maior extensão territorial na MRGTA. A floresta corresponde a $60,9 \%$ do geossistemas da MRGTA, a pastagem $18,4 \%$ e os dendezais $9,6 \%$ da MRGTA.

A floresta foi a UP que mais sofreu alteração ao longo de 30 anos em razão de sua exploração durante a abertura das vicinais e estradas, posteriormente para extrativismo e comércio de madeira para indústria em geral, bem como para produção de carvão vegetal.

A dimensão visual das plantações de dendê inicia-se, a mais ou menos a 10,2 $\mathrm{km}$ após o trevo da PA 151 com a PA 475. Ou seja, após a ponte sobre o rio Moju, já é possível ver os primeiros 5 $\mathrm{km}$ de paisagem desta monocultura rural do dendê, 
de arranjo único que causam impacto paisagístico ao longo PA 475 que liga Moju a Tailândia.

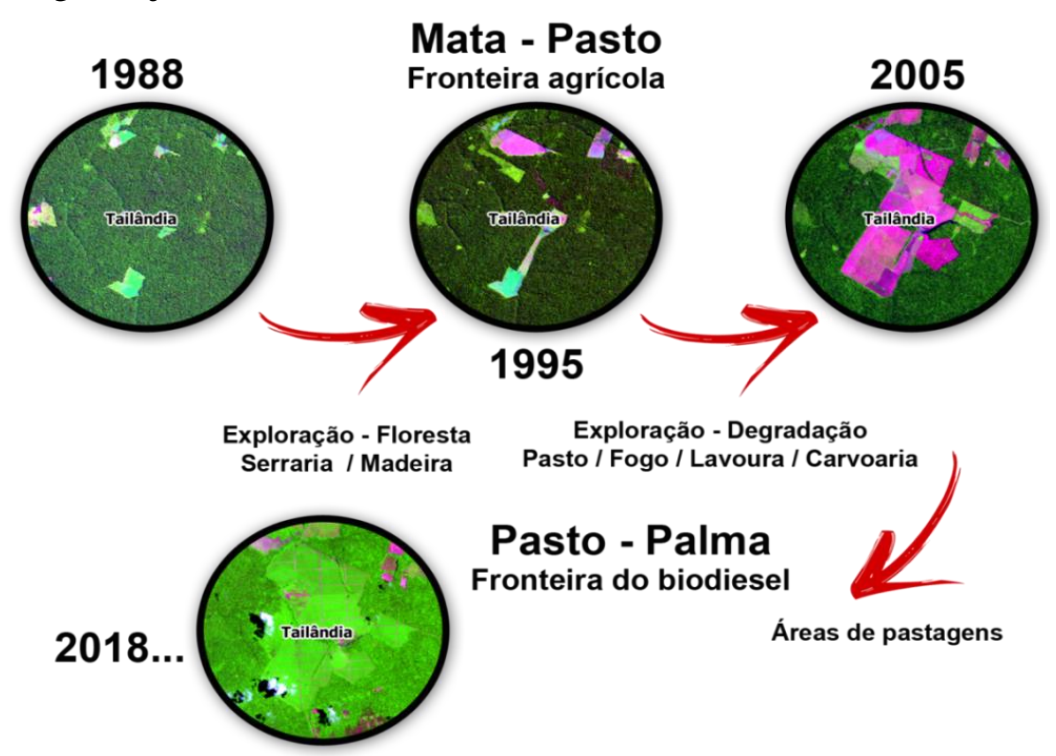

Figura 4. Dinâmica do MUH da paisagem da MRGTA ao longo de 30 anos.

Simultâneo à expansão dos dendezais, verifica-se um processo de urbanização concentrada do núcleo urbano de Moju, Acará, Tailândia, Tomé-Açu e Concórdia do Pará, que impulsionou durante mais de três décadas a abertura da rodovia e ruas marginais na MRGTA. As rodovias, a expansão urbana e a exploração agropecuária são exemplos das perturbações nos MUH rural dessa microrregião.

As rodovias, estradas e ramais da área urbana e dos dendezais possuem uma geometria bem características, correspondendo aos arruamentos pavimentados dos núcleos urbanos (Figura 6a) e os terraplanados por onde se deslocam tratores, ônibus e outros veículos necessários ao transporte de mão-de-obra, plantio e manutenção das culturas, conforme Figura 32b.

As estradas, ruas, vicinais e arruamentos do dendezal na MRGTA totalizaram 23.541,18 km. Destas vias de circulação dos dendezais correspondem a $36,5 \%$, perfazendo $8.601,75 \mathrm{~km}$ (Figura 6b).

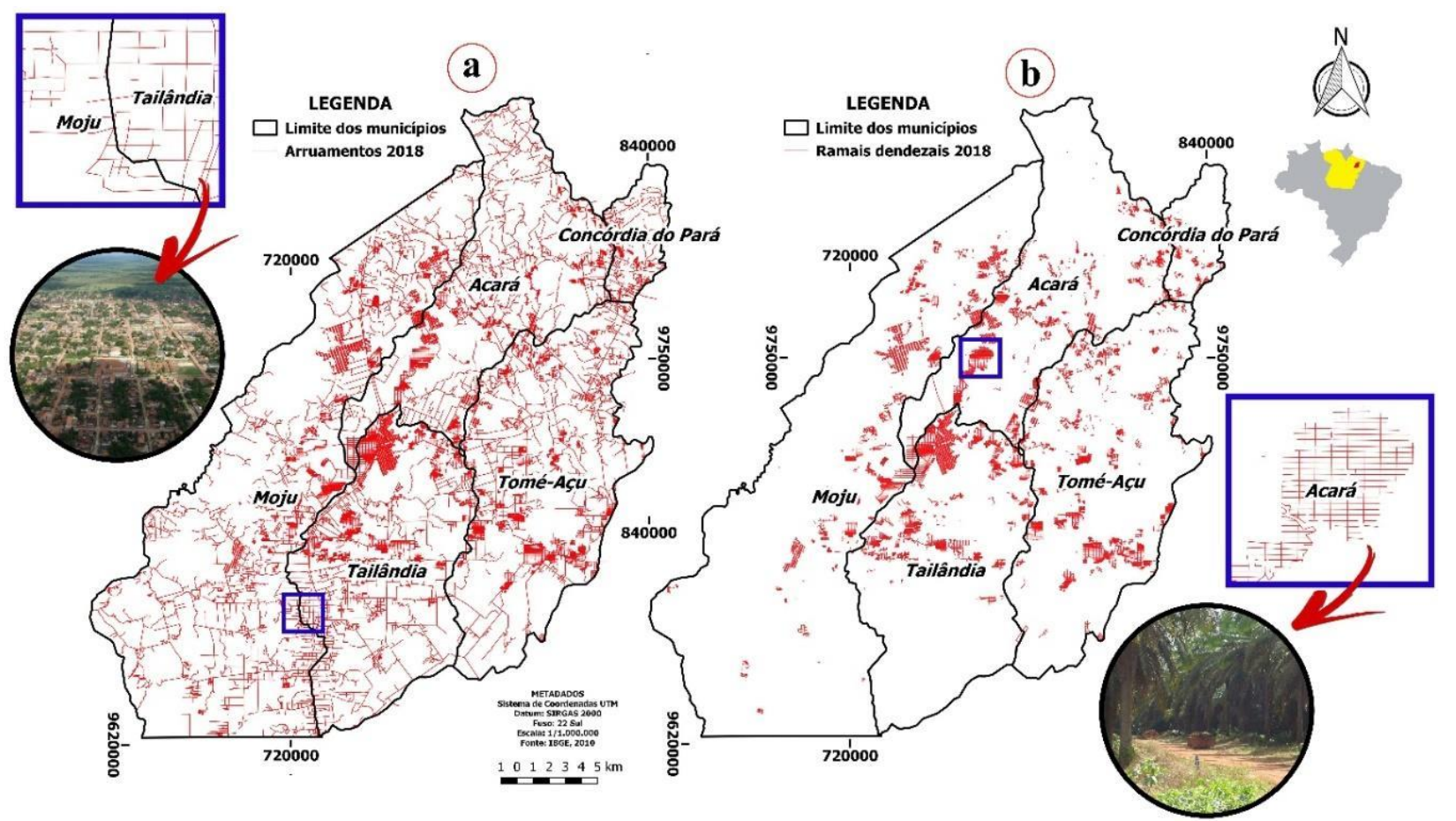

Figura 6. Padrão das estradas e dos ramais dos talhos de dendê na MRGTA. 
Os geofácies das estradas, ruas, vicinais que a instituição pública, se tornou o principal agente regulador do processo de construção, pavimentação da infraestrutura necessária a garantir o movimento de pessoas, mercadorias, informação, decisões e ideias, que vai desencadear um geossistemas de uso e cobertura da terra complexo, envolvendo entre outras, variáveis como a densidade demográfica, a renda da população, a produção da indústria, a urbanização e atualmente o agronegócio do dendê.

\section{Geossistema dos recursos hídricos}

A Terra é chamada de "planeta água", pois dois terços de sua superfície terrestre são cobertos por essa substância na forma de mares, oceanos, rios, lagos; abaixo dela na forma de água subterrânea e na umidade do solo; na atmosfera e, também, no vapor d' água (Whately e Campanili, 2016).

Através do ciclo hidrológico, a água se constitui em uma substância limpa, segura e renovável, que nem sempre está bem distribuída no espaço e no tempo, sendo assim, é importante que seu uso seja gerido com eficiência, para que todos possam ter acesso a esse bem, que é essencial à existência de vida na Terra (Villela e Mattos, 1975; De Carli, 2015).

Contudo, no cenário do crescente desenvolvimento econômico, é vital a elaboração de estudos sobre os usos e abusos da água, uma vez que, apesar de renovável, é um fluído finito (Villela e Mattos, 1975).

Além disso, com o acelerado processo de crescimento e desenvolvimento da sociedade, é notável uma intensa degradação do ambiente, em especial, da água do planeta (Lago e Pádua, 2017). Nesta ótica, Alves et al. (2018) ressaltam os problemas da superexploração local dos recursos naturais como a água, decorrentes principalmente das condições socioeconômicas que infringem as limitações do meio ambiente natural.

É importante destacar também que, em 2014, o Brasil já presenciou eventos de escassez de água, que deixou às claras as limitações e as dificuldades de se garantir a disponibilidade dessa substância, em quantidade e qualidade, quando os níveis de precipitações ficam muito abaixo do esperado, afetando o abastecimento urbano e as atividades rurais, dentre outros (Lopes, 2015).

No contexto rural, a água é muito utilizada, de um modo geral, na criação de animais e no processo de irrigação de plantações, deixando ser apenas um elemento natural para ser considerado um insumo no processo produtivo, dotado de valor econômico (Araújo, 2000).
Ainda, segundo o autor supracitado, esse insumo natural, indispensável à vida, tem sido tratado como um recurso abundante disponível gratuitamente, sendo motivo de preocupação.

A utilização das águas superficiais ou subterrâneas na irrigação, visando suprir as deficiências pluviais na produção do agronegócio, tem sido analisada de diversas maneiras no Brasil, principalmente, com relação às técnicas de irrigação, bem como no que concerne os conflitos por água no âmbito das relações capitalistas do agronegócio (Kaltner et al., 2004; Furlan Júnior et al., 2006; Thomaz Junior, 2010), pois a água é fundamental no metabolismo das plantas, e a redução na sua disponibilidade pode afetar o crescimento, o desenvolvimento e a produtividade das culturas (Ferreira et al., 2016).

No nordeste paraense, na cadeia do agronegócio do dendê, o geossistema hídrico é imprescindível ao cultivo do cacho e na produção de derivados do dendê (Elaeis guineenses) (Müller e Alves, 1997; Müller et al., 2006).

O agronegócio do dendê na MRGTA carece dos geótopos da rede hídrica, nascentes, águas subterrâneas para cultivo e beneficiamento do fruto fresco colhido, para transformá-los, por exemplo, em óleo (Alves et al., 2018).

De acordo com Müller et al. (2006), para produzir uma tonelada de óleo de dendê utiliza-se em média de 6, $2 \mathrm{mil} / \mathrm{m}^{3}$ de água.

Estamos diante de uma agroindústria, que amparada pelo discurso de geração de emprego, renda e inclusão social, monopolizado o geossistemas do uso da terra e agora do geossistemas dos recursos hídricos.

Assim, é importante traçar um panorama da morfometria do geossistemas hidrológico da MRGTA, mostrando as características fisiográficas das geofácie e geótipos (área e forma das SBH, curso d'água, tipo de rede de drenagem, dentre outros) que contribuem para o desenvolvimento da unidade de paisagem da dendeicultura.

\section{Geossistema hídricos nas geofácies de sub- bacias da MRGTA}

A Microrregião de Tomé-Açu (MRGTA) possui cinco geofácie de Sub-Bacias Hidrográficas (SBH), desmembradas, com relação ao limite da microrregião e suas terras drenadas por uns determinados cursos d'água e, limitadas perifericamente por um divisor de água, conforme preceitua Villela e Mattos (1975).

A primeira sub-bacia identificada é a do rio Bujaru (SBH-1), seguida pela SBH-2 do rio Ubá, $\mathrm{SBH}-3$ do rio Mamorama, $\mathrm{SBH}-4$ do rio Moju e, 
por fim a SBH-5 do rio Acará, em ordem crescente de área.

O município do Moju, após definição automática dos divisores de água através do TauDEM, obteve-se dentro do seu limite municipal, três das cinco geofácie de sub-bacias da MRGTA, sendo estas as sub-bacias do rio Ubá, rio Mamorama e rio Moju.

Ainda, no contexto de individualização das geofácie de sub-bacias hidrográficas, sublinha-se a grande extensão da sub-bacia do rio Moju (SBH-4) não fica restrita aos limites fronteiriços municipais dessa microrregião. Outras geofácies de terras drenadas se estenderam para além dos limites político-administrativos municipais, são as geofácies de sub-bacias do rio Moju (SBH-4) e rio Acará (SBH-5).

Ainda quanto à geofácies de terra drenadas da microrregião de Tomé-Açu, identificou-se que essas possuem geótopos variáveis de tamanhos e densidade de corpos hídricos, destacando-se a SBH-5 do rio Acará, com 13.846,12 km² sobre os municípios de Acará, Tailândia e Tomé-Açu, representando a maior área de captação natural da água de precipitação da região.

Nesta sub-bacia, a extensão do geótopo do curso de água é de $2.169,72 \mathrm{~km}$, correspondendo também a maior hierarquia fluvial ( $5^{\mathrm{a}}$ ordem), fato que classifica a região com o maior grau de ramificação, tendo como base os geótopos dos canais analisados.

Já a sub-bacia do rio Moju, com 4.743,21 $\mathrm{km}^{2}$, é a segunda maior geofácie de área drenada, seguido do rio Mamorama (SBH-3), com uma geofácie de $2.132,11 \mathrm{~km}^{2}$, rio Ubá ( $\left.\mathrm{SBH}-2\right)$, com $1.261,58 \mathrm{~km}^{2}$ de geofácie e, rio Bujaru (SBH-1), com de $610,59 \mathrm{~km}^{2}$ geofácie.

Ainda quanto à caracterização do geossistema hidrológico da MRGTA, constatou-se que as geofácie das SBH não são sujeitas a grandes enchentes, conforme o coeficiente de compacidade $(\mathrm{Kc})$.

Ainda quanto aos valores de Kc das subbacias, constatou-se que a mais irregular, e não sujeita a grandes enchentes é a do rio Moju ( $\mathrm{SBH}-$ 4) com 3,20 de Kc, seguida, respectivamente, pelas sub-bacias do rio Ubá, rio Acará, rio Bujaru e rio Mamorama, com 2,67, 2,31, 2,22 e 1,99 de Kc respectivamente.

Confrontando os valores de coeficiente de compacidade $(\mathrm{Kc})$ com os de fator de forma (Kf), revela-se mais uma vez que, as geofácie de subbacias em análise não estão suscetíveis à enchente, mesmo na ocorrência de intensa precipitação, conforme preceitua Andrade et al. (2013), que também é confirmado pela drenagem regular, pois as densidades de drenagem (Dd) estão entre 0,5 e $1,5 \mathrm{~km} / \mathrm{km}^{2}$ (VILLELA; MATTOS, 1975).

Os resultados de sinuosidade apontam que os geótopo de canais são curvos, pois estão próximos de Is de 2,0. Os valores superiores caracterizam os canais como tortuosos e o valor intermediário indicam formas transicionais, regulares e irregulares (SCHUMM, 1963).

Os geótopos de redes de drenagem das SBH da MRGTA são constituídos por cursos d'água principais perenes e canais secundários intermitentes ou efêmeros e para a manutenção da água nas geofácie das $\mathrm{SBH}$, é indispensável contabilizar a área necessária para se manter 1 (um) metro de canal de escoamento fluvial, definido pelo coeficiente de manutenção $(\mathrm{Cm})$.

Neste parâmetro, identificamos que na MRGTA, a área mínima vital para a manutenção de um metro do canal de escoamento, em uma subbacia, é de 3.244,75 km² na SBH-4 (rio Moju) e a área máxima foi de $6.381,52 \mathrm{~km}^{2}$ (SCHUMM, 1963).

Apesar da geofácie das sub-bacia hidrográfica do rio Moju ter maior distância vetorial do canal principal $(195,90 \mathrm{~km})$ e maior elevação $(72 \mathrm{~m})$, essa geofácie hidrográfica tem menor declividade dos cursos d' água, em razão do gradiente de canais $(\mathrm{Gc})$ de 0,20 .

Todavia, o maior valor dado pela relação entre a altitude máxima da bacia e o comprimento do canal principal (Gc), proposto por Horton (1945) apud Villela e Mattos (1975) é da geofácie da SBH do rio Bujaru $(0,84)$, indicando que essa região tem maior declividade de cursos d'água, portanto, maior escoamento superficial.

A hierarquia dos geótopo dos rios (canais), que é a organização natural de um rio, ocorre por ordem de menor volume de água (canais de $1^{\circ}$ ordem), advindo do ciclo hidrológico das águas, dirigindo-se para os rios mais caudalosos.

Neste contexto, os geótopo de drenagem de maior volume de água na MRGTA possuem um comprimento de $701,48 \mathrm{~km}$, sendo que $91,1 \%$ são representados pelos canais de $4^{\mathrm{a}}$ ordem, que não apresentam interrupção no fluxo de suas águas em nenhum período do ano, seja ele de seca, ou de cheias, onde o nível de suas águas nunca fica abaixo da superfície terrestre.

Analisando o percentual dos canais de primeira ordem, Vitte (2005) elucida que quanto maior o número de canais de $1^{\mathrm{a}}$ ordem, maior a fragilidade da paisagem. Assim, esta é a situação da geofácie da SBH-5 do rio Acará, que apresenta $62,7 \%$ do total de canais de primeira ordem, (673 canais).

Portanto, mesmo essa geofácie sendo superior em área de extensão e, por conseguinte, 
maior área de captação de chuva, a sub-bacia do rio Moju, com seus 310 canais de primeira ordem, podem sofrer impactos antrópicos e de processo erosivo pluviométrico, determinado por fatores físicos (declividade, tipos de solo) e econômicos (uso e ocupação) dos diversos ambientes às interferências antrópicas, caracterizando sua fragilidade ambiental, conforme preceitua Almeida et al. (2016).

As geofácie da SBH-3 (Rio Mamorama) e SBH-4 (Rio Moju) apresentaram ordenamento igual à $4^{\mathrm{a}}$ ordem, sendo enquadradas como pequenos geótopos de terra drenadas.

Como os corpos hídricos que compõem um sub-bacia são classificados de acordo com sua ordem de ramificação, também podemos representar essa importância por meio da Relação de bifurcação (Rb) dos geótopos de canais da MRGTA. A Rb é a divisão ou separação dos geótopos de cursos d'água em ramos ou braços (tal como uma forquilha), definida por Horton, em 1945.

A relação de bifurcação, de acordo Villela e Mattos (1975) pode variar de 2,50 a 9,00. Considerando que na MRGTA, a média de bifurcação dos geótopos de canais de $1^{\text {a }}$ ordem para os de $2^{\text {a }}$ ordem foi de 3,58, conclui-se que, em média, cada geótopo de rio de $2^{\mathrm{a}}$ ordem recebe contribuição de 3 rios de $1^{\mathrm{a}}$ ordem, tornando-os mais caudalosos.

Neste cenário, destaca-se a geofácie SBH1 (rio Bujaru) e SBH-3 (rio Mamorama) que têm os maiores valores $\mathrm{Rb}$, pois os canais de $2^{\mathrm{a}}$ ordem do rio Bujaru e rio Mamorama recebem contribuição de 4 canais de $1^{\text {a }}$ ordem cada, representando maior volume de água no exutório.

A média de contribuição que os canais de $3^{\mathrm{a}}$ ordem recebem dos canais de $2^{\mathrm{a}}$ ordem, nas subbacias em análise, foi de 5,24, e os de $4^{\mathrm{a}}$, com relação aos de $3^{\text {a }}$ ordem, foi de 4,16 , sustentando que, os de $3^{\mathrm{a}}$ ordem recebem a contribuição média de cinco canais de $2^{\mathrm{a}}$ ordem, e os de $4^{\mathrm{a}}$ recebem a contribuição média de quatro canais de $3^{\mathrm{a}}$ ordem.

De acordo com Villela e Mattos (1975), as maiores relações de bifurcação verificadas foram entre os canais de $4^{\mathrm{a}}$ e $5^{\mathrm{a}}$ ordem, tendo os canais de $1^{\text {a }}$ à $3^{\text {a }}$ ordens comportamentos similares de bifurcação. Contudo, na MRGTA, sobreleva deste resultado o rio Ubá, onde um canal de $3^{\mathrm{a}}$ ordem recebe a contribuição de nove canais de $2^{\mathrm{a}}$ ordem.

No município de Concórdia do Pará está a menor geofácie de terra drenada (sub-bacia $\mathrm{SBH}$ ), "banhado" pelo rio Bujaru, conforme a Figura $7 \mathrm{a}$.
Ainda na Figura 7a, ilustra-se que as geofácies de SBH da MRGTA são alongadas, também comprovadas pelos valores obtidos nos índices de compacidade, circularidade e fator de forma, o que indica pouca susceptibilidade a enchentes, em condições regulares de precipitação.

$\mathrm{Na}$ Figura $7 \mathrm{~b}$, visualiza-se a hierarquia dos geótopos de rede de drenagem da MRGTA. Segundo Veiga et al. (2013) processo de hierarquização dos geótopos de canais permite identificar suas interligação e, sobretudo, possibilita fazer analogias acerca dos percursos dos segmentos fluviais e de seus tributários como, por exemplo, sobre os segmentos de rios que vão transpor as plantações de dendê (Figura 7b).

Em outras palavras, com a organização natural dos geótopos dos rios da MRGTA, evidenciam-se os geótopos hídricos de menores volumes de água, e os geótopos hidrológicos que contribuem para o ciclo das águas, e darão volume aos rios mais caudalosos, como o rio Moju e o Acará.

Também na Figura 7, ilustra-se a forma elíptica das geofácie das sub-bacias dessa microrregião, que facilita o escoamento superficial, decorrente de precipitações uniformes, produzindo, portanto, menor probabilidade de enchentes.

Com a distribuição da geofácie dos dendezeiros sobre o geossistema hídrico (Figura $7 b)$ percebe-se que a água é um dos principais insumos na cadeia agroindustrial de óleo de palma, e esta discussão está ausente quando se fala das "exigências ambientais para se plantar o dendê" (Muller e Alves, 1997).

Quando se mencione o balanço hídrico, este é resumido e referido à quantidade e intensidade de chuvas necessária ao seu desenvolvimento.

Desta forma, o geossistema hidrológico não aparece quando se fala do pré-viveiro e do viveiro. Barcelos et al. (1987) não incluem a existência de corpos hídricos entre as exigências ecológicas (temperatura, precipitação, insolação, solos) para o cultivo do dendezeiro.

A não inclusão é contraditória, pois reconhecem que "o viveiro deve ser localizado próximo a uma fonte d'água para alimentar as mudas nele contidas, de acordo com suas necessidades, que são de aproximadamente $80 \mathrm{~m}^{3 /}$ dia/ha de viveiro, durante a estação seca" (Barcelos et al., 1987). 


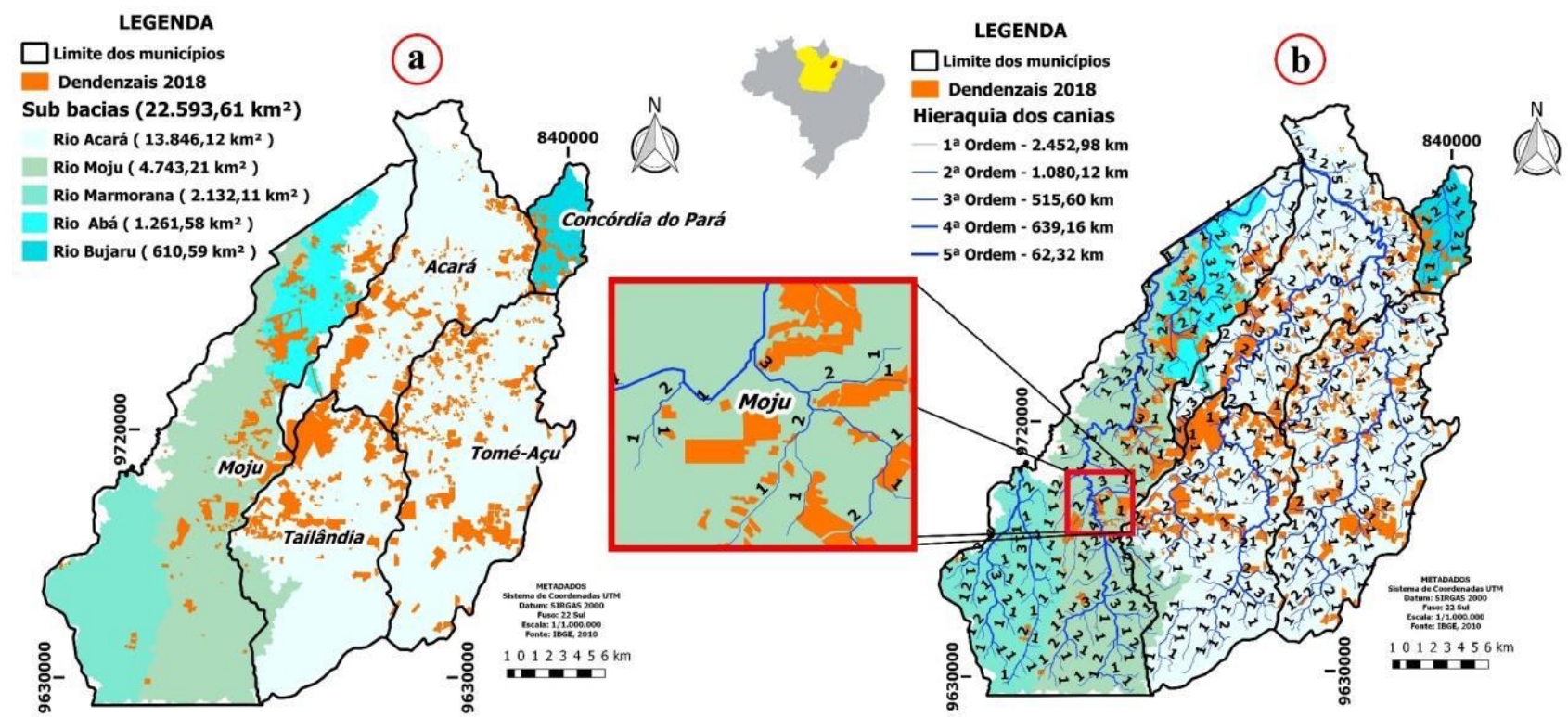

Figura 7. Limite do geossistema dos recursos hídricos da MRGTA.

Portanto, revela-se que na MRGTA as geofácies das sub-bacias hidrográficas estão sendo perturbadas e vem passando por uma intensa transformação, como consequência do avanço da expansão do cultivo do dendê sobre nascente e rios da região, provocando constantes mudanças no geossistema hídrico natural deste espaço Amazônico (Da Silva et al., 2017; De Carvalho et al., 2014).

\section{Geossistema climatológico}

Um dos geossistema que se destaca como determinante na análise integrada da paisagem, sendo considerado um todo sistêmico, é climatológica, principalmente por ser um geossistema revelador de fragilidade da paisagem de subsistemas físico e bióticos (Zacharias, 2010).

Como os dendezeiros necessitam de condições específicas da atmosfera e de água para se desenvolver, pode-se afirmar que interação dinâmica e instável dos atributos do geossistema climatológico representa uma característica única e indissociável para produção do cacho.

Assim, os geótopos das condições média da atmosfera terrestre, de acordo com a Classificação de Köppen-Geiger (1993 apud Aparecido et al. (2016), identificados na MRGTA, foram duas, sendo o primeiro correspondendo dois de geótopos do clima tropical úmido $(A f 2$ e $A f 3)$ e três do geótopos do tipo tropical de monção ( $A m 1$, Am2 e Am3) (Martorano et al., 1993).

O Af2 é caracterizado por uma precipitação pluviométrica média anual que varia de entre $2.851 \mathrm{~mm}$ e $2.489 \mathrm{~mm}$ (Figura $38 \mathrm{a}$ ), totalizando um Geossistema climatológico (GC) de 11.153,25 $\mathrm{km}^{2}$, correspondendo a 46,4 \% da MRGTA.
No subtipo $A f$ a precipitação pluviométrica média anual que possui extremos entre $2.600 \mathrm{~mm}$ e $2.300 \mathrm{~mm}$ (Figura 8a). De forma geral, o tipo $A f$ corresponde geótopo de condições média da atmosfera terrestre denominado de clima tropical úmido, com a ocorrência de precipitação do mês menos chuvoso igual ou superior a $60 \mathrm{~mm}$ (Figura 38a), onde não há estação seca (Watrin et al., 2011).

A Afl, como precipitações entre $2.489 \mathrm{~mm}$ e $2.332 \mathrm{~mm}$, correspondendo a um GC de $8.742,42$ $\mathrm{km}^{2}$ ou $36,3 \%$ dessa microrregião.

Sobre 1.372,78 $\mathrm{km}^{2}$ de geótopo de dendezeiros é predominante a classificação climática Af2 que apresenta precipitação pluviométrica média anual, variando entre $2.500 \mathrm{~mm}$ e $3.000 \mathrm{~mm}$ (Figura $8 \mathrm{a}$ e $8 \mathrm{~b}$ ).

Sobre Af3 há $847,43 \mathrm{~km}^{2}$ de dendezais que recebem uma precipitação pluviométrica média anual entre $2.000 \mathrm{~mm}$ e $2.500 \mathrm{~mm}$.

Dendeicultura sobre $A m 3$ é representado por uma área de $12,80 \mathrm{~km}^{2}$. O geótopo de clima do tipo monção $(A m)$ apresenta característica de clima de ventos com moderada com estação seca, com ocorrência de precipitação média mensal inferior a $60 \mathrm{~mm}$.

O clima Am na MRGTA é reconhecido por apresentar uma precipitação pluviométrica média anual superior a $2.400 \mathrm{~mm}$.

Na microrregião de Tomé-Açu os subtipos de clima "Am" foram Am1, Am2 e Am3 (Figura $38 b$ ), totalizando geofácies de 759,79 $\mathrm{km}^{2}$, $789,02 \mathrm{~km}^{2}$ e $2.557,69 \mathrm{~km}^{2}$, nesta ordem. Essas faixas climáticas correspondem a 3,1\%,3,2\% e $10,6 \%$ da MRGTA. 
Ainda sobre subtipos de clima Am1 e Am2 quantificou-se $7,40 \mathrm{~km}^{2}$ e $2,76 \mathrm{~km}^{2}$ de dendezais, nesta ordem, conforme Figura $8 \mathrm{~b}$.

O geossistemas climatológicos do tipo tropical equatorial úmido $(A f)$ e monções $(A m)$ ficaram sobre uma extensão territorial de $19.895,67 \mathrm{~km}^{2}(82,82 \%)$ e $10.291,23 \mathrm{~km}^{2}(42,83 \%)$ respectivamente, correspondendo a um perfil de temperaturas médias mensais sempre superiores a $18^{\circ} \mathrm{C}$.

Por fim, a média da precipitação anual na região revela os totais pluviais ofertados pela atmosfera ao longo do ano, que variam na área de plantio, todavia existem áreas a nordeste que registraram precipitação acima de $3000 \mathrm{~mm}$, onde o predomínio do clima tipo $A f$, conforme Figura $8 \mathrm{~b}$.

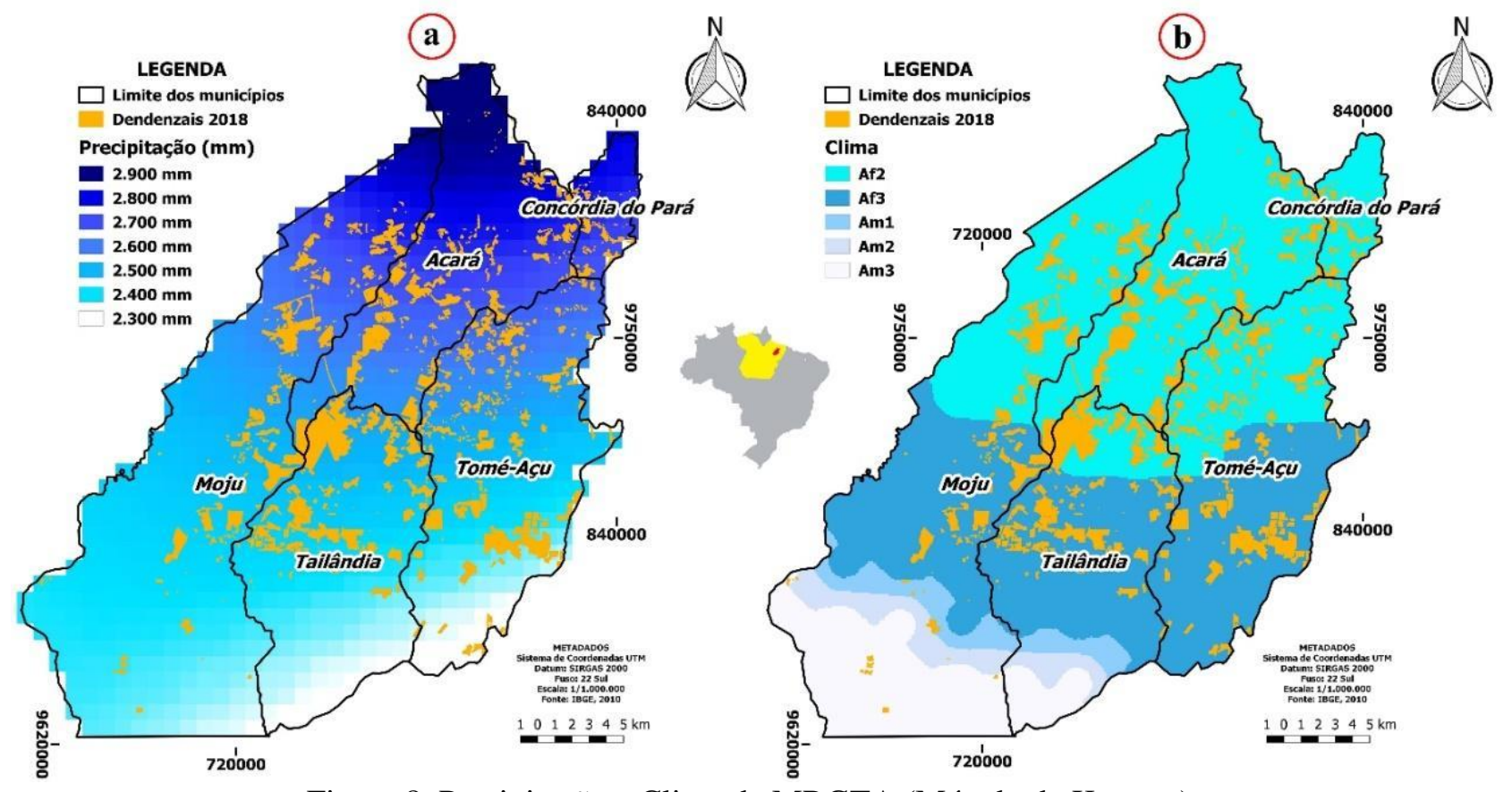

Figura 8. Precipitação e Clima da MRGTA (Método de Köppen).

Os geossistemas climatológico, do solo e da temperatura, são as principais condições que favorecem as mudanças nas UPs e, por conseguinte na expansão da palma de óleo ou dendê (Elaeis guineenses Jacq.) na MRGTA, pois o cruzamento direto representa o potencial agroecológico das terras (Ramalho Filho et al., 2010). Logo, verificase a importância de se preservar e estimular a manutenção desses geossistemas para a estabilidade da paisagem.

\section{Geossistemas de solo}

De acordo Ramalho Filho et al. (2010), a avaliação do geossistema do solo, por meio de suas geofácies dos aspectos geológicos, geomorfológicos e pedológicos, constitui-se um aspecto relevante para a o geótopo de dendezeiro, porque as características específicas das geofácies de solo vão, por exemplo, interferir no volume das raízes e, consequentemente, na disponibilidade de nutrientes para os dendezais, além do que o cruzamento direto entre a textura do solo, por exemplo, deve auxiliar as avaliações das áreas suscetíveis à erosão e de impedimento à mecanização.
Neste cenário, a estrutura da geofácie geológica principal da área em análise é do Grupo Barreiras $(T Q b)$, que corresponde a cobertura sedimentar terrígena continental e marinha, sugerindo, que segundo Sauer et al. (2004), sugere inicialmente que a MRGTA esteve mergulhada ao Oceano Atlântico.

O geótopo de $T Q b$ ocorre predominantemente em $78,9 \%$ da microrregião, mais especificamente na sub-bacias do Rio Acará cobrindo correspondendo a uma área de 4.037,29 $\mathrm{km}^{2}$. A geofácies do Grupo Barreiras também está presente no município do Acará em uma área de $3.865,78 \mathrm{~km}^{2}$ e Tomé-Açu (2.781,36 km²), conforme Figura 9a.

Nas sub-bacias dos rios Moju e Mamorama, o Grupo Barreiras totalizou uma superfície homogênea de $3.554,03 \mathrm{~km}^{2}$ e 347,87 $\mathrm{km}^{2}$, respectivamente. Ainda na Figura 9a, ilustrase também a extensão da geofácie de sedimentos terciários da formação Barreiras (áreas de terra firme com $1.8684,04 \mathrm{~km}^{2}$ na cor amarela), bem como dos sedimentos inconsolado do Quaternário Subatual e Recente (áreas de sedimentação flúviomarinha). 
A outra geofácie geológica predominante na MRGTA é a formação Ipixuna (Kix) do Período Terciário, constituído por uma sucessão de arenitos e siltitos (Rodrigues, 2001). O Kix é representado na Figura 9a, na cor rosa, correspondendo à superfície de $3.899,23 \mathrm{~km}^{2}$, o que equivale a $15,33 \%$ da MRGTA.

$\mathrm{Na}$ geofácies de pedologia o Latossolo Amarelo (LA11, LA12 e LA14), de textura argilosa (KER 1997), tem maior predominância, correspondendo a uma região de $13.898,83 \mathrm{~km}^{2}$ $(57,8 \%)$ na MRGTA.

O Latossolo Amarelo, de textura média, equivale a 32,6\% da MRGTA, totalizando uma área de $7.842,86 \mathrm{~km}^{2}$. Na Figura $9 \mathrm{~b}$, representa-se a distribuição geomorfológica, com notoriedade para classe Dissecação ao Tabular 12 (Dt12) com $3.664,53 \mathrm{~km}^{2}$, equivalente a 55,8\% da MRGTA.

Ainda quanto às geofácies de geomorfológica, os municípios de Moju, Acará e Tomé-Açu possuem maior diversidade de classes, com destaque para a sub-bacia do Rio Moju (SBH4) $\mathrm{com}$ as classes geomorfológicas: $A f$ (Acumulação Planície Fluvial), Dc22 (Dissecação Convexa 22), Dt12 (Dissecação ao Tabular 12), $\mathrm{Ha}$ (Aluviões Fluviais), Kix (Formação Ipixuna) e Pru (Pediplano Retocado Desnudado).
Já sobre a geofácie do tipo Latossolo Amarelo, de textura argilosa, existem 1.628,69 km² de área ocupada pelos dendezais. No solo do tipo Latossolo Amarelo de textura média há 675,27 km² de dendezais, seguido do Gleissolo Háplico com $28,86 \mathrm{~km}^{2}$ (Figura 9c).

Com relação à geofácie geomorfológica, os dendezais estão sobre Dissecação ao Tabular 12 (Dt12), seguido de plantíos sobre Dissecação Convexa 33 (Dc33), Pediplano Retocado Desnudado (Pru), dissecação Convexa 22 (Dc22), Acumulação Planície Fluvial (Af), representando $1.99,60 \mathrm{~km}^{2}, 155,19 \mathrm{~km}^{2}, 123,49 \mathrm{~km}^{2} \mathrm{e} 42,68 \mathrm{~km}^{2}$, respectivamente (Figura 9b).

Também, a Figura 9c, está representada os limites das geofácies pedológico, sobressaindo à classe LA11 (Latossolo Amarelo) que representa sozinha $37,22 \%$ da MRGTA. Sobre a geofácie Ipixuna ( $K i x$ ) (sedimentar, Arenitos e Siltitos) há $481,75 \mathrm{~km}^{2}$ geótopo de monocultura oleaginosa, seguido das plantações sobre geofácie Aluviões Fluviais ( $\mathrm{H}$ a - Sedimentar; Areias, Siltes, Argilas e Cascalhos) e Coberturas Detrito-Lateríticas Patogênicas ( $T p d l$-Sedimentar; Areias, Siltes e Argilas Diversas), nesta ordem correspondendo a $66,58 \mathrm{~km}^{2}$ e $8,38 \mathrm{~km}^{2}$ da MRGTA (Figura 9a). 

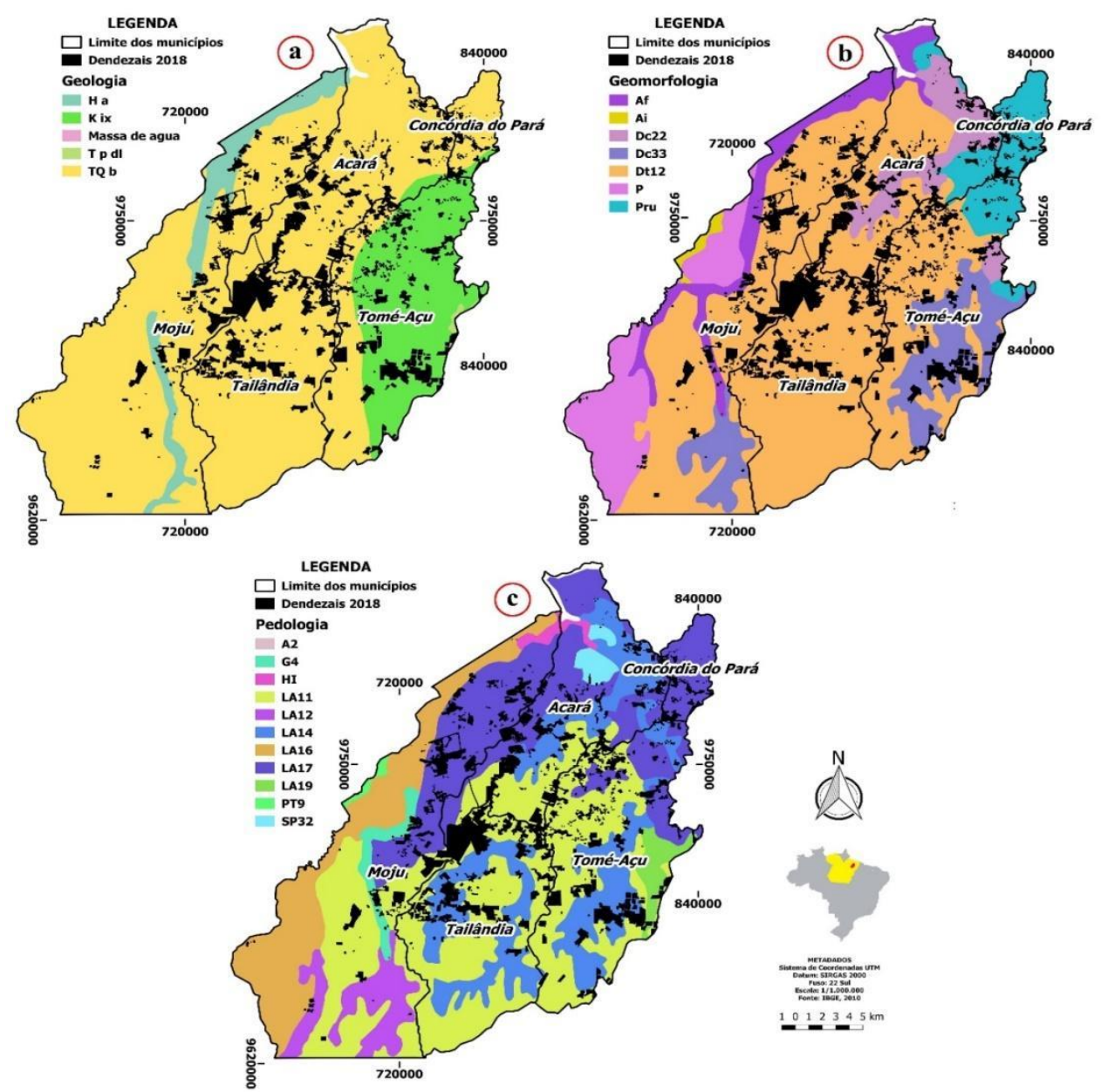

Figura 9. Limite das geofácies geológico, geomorfológico e pedológico da MRGTA.

Os geossistemas de solos nas sub-bacias da região em estudo são distintos, diferenciando-se em extensão entra sub-bacias e municípios, e por conseguintes sobre o uso e cobertura da terra, principalmente no geótopo da agricultura de dendê que tem sua extensão predominantemente sobre o geofácie $T Q b$ (grupo barreiras, sedimentar erosiva, sedimentos areno argilosos, arenosos, argilosiltosos e conglomeráticos), totalizando $1.779,30$ $\mathrm{km}^{2}$. Com o geossistema de solo, revela-se que MRGTA apresentam boas condições físicas de retenção de umidade e boa permeabilidade que vai definir a quantidade de água armazenada no solo e que pode ser aproveitada pelo geótopo dos dendezais. (Ker, 1997).

\section{Geossistema de relevo}

O conjunto de características do geossistema de relevo, assim como do solo melhoram o entendimento das unidades de paisagem da microrregião de Tomé-Açu. Neste sentido, a unidade geossistêmica com maiores valores de elevações, que delimitam as sub-bacias hidrográficas $(\mathrm{SBH})$, foram a do rio Ubá, rio
Mamorana e rio Moju, correspondendo a 36\% $\left(8.136,90 \mathrm{~km}^{2}\right)$ da área em análise.

As geofácies de declividades utilizadas na caracterização das Mosaicas de Unidades Homogêneas (MUH) foram baseadas na metodologia utilizada pela Embrapa (2006). Assim, as geofácies de declividade adotada foram: Plano 0 a 3\%, Suave ondulado 3 a $8 \%$, Ondulado 8 a $20 \%$, Forte ondulado 20 a $45 \%$, Montanhoso > 10.

As geofácies de domínios suaves ondulados e ondulados foram superfície topográfica de maior primazia, correspondendo a $84,16 \%\left(20.218,80 \mathrm{~km}^{2}\right)$ na MRGTA. Nestas estão às superfícies de topografia horizontal ou pouco movimentada, constituída por um conjunto de colinas com declives moderados ou formando morros.

As superfícies ondulada e forte ondulada de maior valor areal estão no município do Moju, principalmente nas sub-bacias do rio Moju ( $\mathrm{SBH}-$ $\left.4=4.136,98 \mathrm{~km}^{2}\right)$, rio Ubá $(\mathrm{SBH}-2=1.150,82$ $\left.\mathrm{km}^{2}\right)$ e rio Mamorana $\left(\mathrm{SBH}-3=768,96 \mathrm{~km}^{2}\right.$ ), totalizando $26,4 \%\left(6.354,76 \mathrm{~km}^{2}\right)$ da área em estudo. A SHB-5 (rio Acará) tem 54,94\% 
$\left(13.199,58 \mathrm{~km}^{2}\right)$ de sua superfície sobre geofácies de terreno ondulada e forte ondulada.

O domínio geofácies do tipo montanhoso que segundo Ribeiro e Da Glória Alves (2008) é uma superfície de topografia vigorosa com predomínio de formas acidentadas, usualmente constituída por morros, corresponde na microrregião uma superfície de $3,86 \mathrm{~km}^{2}$.

Neste contexto, $51,92 \%\left(12.472,37 \mathrm{~km}^{2}\right)$ do geossistema solo da região está em superfície mais suave, apresentando, em geral, uma nítida diferenciação entre horizontes principais do solo (camadas).

Do contrário, mais de $900 \mathrm{~km}^{2}$ (3,74\%) geofácies de relevo mais íngremes (forte-ondulado e Montanhoso) na MRGTA estão sobre geótopo rasos como menor diferenciação entre horizontes.

De acordo com Cunha e Guerra (2011), solo raso tem um acentuado escoamento superficial de água, que favorece a remoção do material edafizado, decorrentes de processo de desintegração física e química de rochas e minerais, que varia com a profundidade do mesmo.

Na Figura 10a, tem-se destaque para uma região montanhosa (quadrado vermelho) com mais de $>45 \%$ de declividade, onde o relevo acentuado tem um escoamento superficial rápido, propício à erosão e na Figura 10b, revela-se as geofácie de altimetria que é importante para definição de áreas prioritárias à plantações de dendezeiros.

Com o geótopos de dendezais sobreposto as geofácies de declividade e elevação, visualizase que este está distribuído sobre os geótopos de terreno plano a suave-ondulado, demonstrando que grande parte de microrregião apresentou condições favoráveis tanto para habitação urbana quanto para a prática do agronegócio com o auxílio de maquinário, devido à característica da área de possuir relevos planos e/ou com suaves ondulações que são regiões favoráveis à mecanização agrícola e não favorecendo a erosão.

De forma geral, o geossistema de relevo é importante para definição de áreas prioritárias para construções de edificações, estradas, pontes, pastagens e plantações que, por conseguinte influenciar nas condições hídricas e térmicas dos solos.

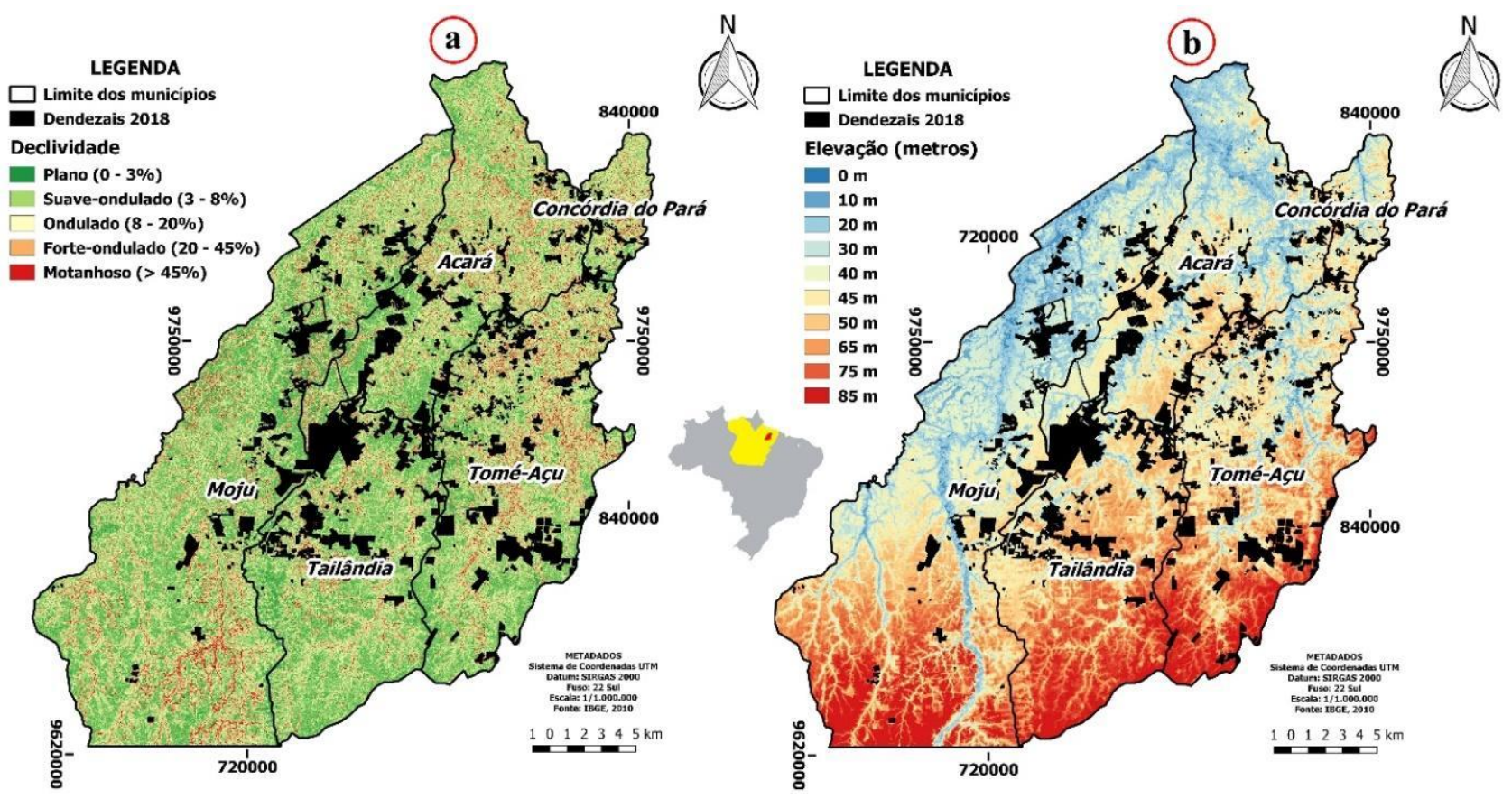

Figura 10. Limite das geofácies de declividade e altimetria da MRGTA.

Dentro dessa definição, o geossistema de relevo na microrregião de Tomé-Açu, é caracterizado por baixos platôs aplainados (tabuleiros), terraços e várzeas, que variam entre 10 e $90 \mathrm{~m}$ de altitude, que é uma geótopos de topografia são importantes na distribuição das espécies vegetais, porque influencia no metabolismo das plantas e, por conseguinte na produção da agricultura, em especial da dendeicultura.

\section{Análise do Geossistema, Território e Paisagem (GTP)}

O Geossistema, Território e Paisagem (GTP), como tema deste capítulo, permitiu aplicar 
as delimitações sistemáticas da paisagem rural em unidades hierarquizadas, compostas por seis níveis, subdivididos em unidades superiores (zona, domínio e região) e unidades inferiores (geossistema, geofácies e geótopo), com o objetivo a captar a associação de diferentes elementos geossistêmicos da MRGTA.

Martinelli e Pedrotti (2011), afirmam que a paisagem é a forma espacial do presente, porém é testemunha das formas passadas que ainda persistem ou não.

Desse jeito, observou-se que os níveis inferiores das paisagens da MRGTA encontram-se bem diferente dos tempos passados, representando uma pluralidade de formas e estruturas distintas de Unidades de Paisagem (UPs) que passou por várias fases transformações (desmatamento, queimadas, pasto, agricultura, agronegócio, etc.), produzindo variações nos Mosaico de Unidades Homogêneas (MUH), com tendência a homogeneidade, a exemplo da expansão da monocultura do dendê e heterogeneidade, a exemplo dos UCT, e suas geofácies (Zacharias, 2010; Glass, 2013).

Neste cenário, o geossistema das subbacias tem um papel fundamental na evolução das geofácies e dos geótopos, cujas estruturas e dinâmicas resultam da interação entre os potenciais ecológicos de clima, geologia, geomorfologia e pedologia, dentre outros que condicionam comportamentos naturais e atividades antrópicas neles desenvolvidos (Monteiro e Rocha, 2013).

O geossistema do solo desvenda as extensões, as diversidades e as variáveis dos locais para boas produções da cultura do geótopos de dendê, assim como o geossistema de relevo condicionam as regiões de exploração dos recursos naturais para o agronegócio, principalmente pelos conhecimentos das geofácies de declividade e altimetria, que são primordiais na interpretação dos processos de transporte gravitacional da água, como por exemplo, no escoamento superficial, erosão, deslizamentos e lugares propensos às cheias, decorrente da terraplanagem das áreas de cultivos.

Segundo Girão e Corrêa (2004), a natureza da elevação, declividade e de solo da MRGTA condicionam maior ou menor rapidez do escoamento superficial da rede de drenagem dos 22.533,61 km de geótopos dos cursos d'água, os quais constituem um importante modelador da paisagem e que vão influenciar do geótopos de microclima e de temperatura, como esclarecem $\mathrm{Da}$ Silva e Dos Santos (2010).

Como a geofácies de topografia predominante na MRGTA é do tipo suaveondulada, Ramalho Filho et al. (2010), esclarece que isso possibilita o uso de máquinas agrícolas, sendo o rendimento (número de horas de trabalho usadas efetivamente) entre $75 \backslash 5$ a $90 \%$. Por fim, a declividade como UP é uma variável topográfica importante na distribuição das áreas de cultivo, porque ela influencia no metabolismo das plantas (Martorano et al., 2011).

A expansão dos dendezeiros, no ritmo atual, pode influenciar, por exemplo, na regulação do geossistema climático se não forem bem manejados, o que impossibilita que outros processos ecológicos ocorram ao longo do tempo, como o acúmulo de matéria orgânica nas geofácies de solo, como a ciclagem de nutrientes, a regulação do geótopos de temperatura, diversidade de microrganismos, a atração de polinizadores e a dispersão de sementes, entre outros (Lumbreras et al., 2003).

O geótopo de dendezal podem gerar alterações a partir dos quais desencadeiam a degradação de áreas que deveriam ser preservadas, como por exemplo, do geótopos de nascentes de cabeceiras, gerando impactos à montante e à jusante dos rios, provocando também desequilíbrio da paisagem (PARK, 1981 apud Cunha e Guerra, 2011; Benda et al., 2017.

Do ponto de vista bertrandiano, revela-se que a paisagem do dendê não pode ser analisada apenas pela aparência, cenário ou vitrine, principalmente em razão das relações sociais que vivificam neste lugar.

Na Tabela 1, apresenta-se uma síntese da combinação espacializada dos geossistemas (geomorfologia, hidrologia e clima); exploração abiótica (solo, vegetação e fauna) e antrópicos (solo exposto/Antropizado), cultura permanente, estradas, uso da terra e impactos das sociedades sobre o ambiente, conforme a hierarquia de seus elementos classificando em unidades superiores e inferiores.

Deste jeito, a Tabela 1, traduz-se no conceito de paisagem global, na qual se tem a preocupação com a interação natureza-sociedade e na análise geossistêmica, que é um sistema territorial regido por leis naturais.

Dependendo do geossistema e da hierarquia de classificação de Bertrand (1971) a atividade do agronegócio nos Mosaico de Unidades Homogêneas (MUH) de solo, de água, de clima, de relevo e de vegetação, forma um conjunto de recursos indispensáveis à produção desta cultivar. Sendo assim, o método Geossistema, Território e Paisagem (GTP) serviu não só para a delimitação e representação cartográfica das áreas, mas principalmente para a detecção dos problemas existentes no local e o grau de responsabilidade da 
ação antrópica sobre os mesmos, assim como o planejamento de estratégias para conter, reverter ou amenizar os impactos já causados.

Contudo, a análise da paisagem sob a ótica bertrandiana (1971), foi uma fundamentação científica, que permitiu entender que a paisagem dessa microrregião caminha pari e passu com a reorganização e a configuração espacial do território do agronegócio, agrupando intencionalidades sociais, que introduzem nos lugares onde aportam novas temporalidades e espacialidades segundo as lógicas dos mercados mundiais do agronegócio do dendê.

Tabela 1. Síntese de classificação da paisagem geossistêmica da MRGTA.

\begin{tabular}{|c|c|}
\hline \multicolumn{2}{|r|}{ Zona } \\
\hline Paisagem & $\begin{array}{l}\text { Zona intertropical; América do Sul setentrional.; Domínio } \\
\text { Amazônico; Possuímos a maior parcela territorial dentro da } \\
\text { Amazônia pan-americana. }\end{array}$ \\
\hline Solo / Relevo & $\begin{array}{l}\text { Limita-se ao norte e ao sul com os escudos cristalinos } \\
\text { brasileiros e das guianas; Planície Amazônica (Aroldo } \\
\text { Azevedo); Planície de terras baixas amazônicas (Ab'sáber); } \\
\text { Planalto (Jurandyr Ross); Imensa área de terras planas e baixas. }\end{array}$ \\
\hline Clima & $\begin{array}{l}\text { Influenciado pela massa de ar Equatorial continental }(\mathrm{mEc}) \text { e } \\
\text { massa de ar Equatorial atlântico (mEa); Tropical superúmido. }\end{array}$ \\
\hline Hidrografia & $\begin{array}{l}\text { Bacia Amazônica; Rio principal desta bacia é o Amazonas que } \\
\text { nasce no Peru e depois percorre o território brasileiro. }\end{array}$ \\
\hline Biogeografia & $\begin{array}{l}\text { Biomas continentais; Maior biodiversidade de plantas, os } \\
\text { animais e os microrganismos. }\end{array}$ \\
\hline Unidade Trabalhada pelo Homem & Climatologia e Mudanças ambientais \\
\hline \multicolumn{2}{|r|}{ Domínio } \\
\hline Paisagem & $\begin{array}{l}\text { Terras baixas florestadas equatoriais; Sedimentos terciários } \\
\text { argilo-arenosos. }\end{array}$ \\
\hline Solo / Relevo & Maciço cristalino e grandes bacias sedimentares \\
\hline Clima & $\begin{array}{l}\text { Massa de ar quente e úmida e instável; Médias térmicas anuais } \\
\text { que variam de } 24^{\circ} \mathrm{C} \text { a } 27^{\circ} \mathrm{C} \text {. }\end{array}$ \\
\hline Hidrografia & Complexo sistema de grande volume de água doce. \\
\hline Unidade Trabalhada pelo Homem & Navegação e Irrigação. \\
\hline \multicolumn{2}{|r|}{ Região Natural } \\
\hline Paisagem & $\begin{array}{l}\text { Matas fechadas e densas, formadas por árvores de grande; } \\
\text { Floresta Equatorial da Amazônia ou Hiléia Amazônica } \\
\text { (Humboldt); Matas de igapó, as matas de várzea e as matas de } \\
\text { terra firme; Rios brancos e negros. }\end{array}$ \\
\hline Solo / Relevo & $\begin{array}{l}\text { Formação Barreiras e Alter do Chão; Altitudes menores que } \\
3.200 \text { metros; Baixo platô de áreas de várzea, teso e terra firme; } \\
\text { Solo composto por Latossolos e argissolos. }\end{array}$ \\
\hline Clima & $\begin{array}{l}\text { As chuvas predominantes são as de convecção; Índice de } \\
\text { pluviosidade média anual entorna de } 1800 \mathrm{~mm} \text {; Baixa } \\
\text { amplitude térmica. }\end{array}$ \\
\hline Hidrografia & $\begin{array}{l}\text { Rede de drenagem de igarapés e rios autóctones; Rios de águas } \\
\text { brancas, negras ou claras. }\end{array}$ \\
\hline Biogeografia & $\begin{array}{l}\text { Vegetação higrófita adaptada a grande quantidade de água; } \\
\text { Grupos vegetais com folhas largas e grandes (latifoliada); Solo } \\
\text { de baixa fertilidade. }\end{array}$ \\
\hline Unidade Trabalhada pelo Homem & Expansão da fronteira agrícola; Lazer e consumo. \\
\hline \multicolumn{2}{|r|}{ Geossistema } \\
\hline Paisagem & $\begin{array}{l}\text { Vegetação e do Uso e Cobertura da Terra; Geossistema } \\
\text { climatológico. }\end{array}$ \\
\hline Solo / Relevo & $\begin{array}{l}\text { Cobertura sedimentar terrígena continental e marinha; } \\
\text { Sedimentos inconsolidado do Quaternário Subatual e Recente; } \\
\text { Baixos platôs aplainados (tabuleiros), terraços e várzeas. }\end{array}$ \\
\hline
\end{tabular}




\begin{tabular}{|c|c|}
\hline Clima & $\begin{array}{l}\text { Clima tropical úmido; Monção com moderada estação seca; } \\
\text { Temperaturas médias mensais sempre superiores a } 18^{\circ} \mathrm{C} \text {. }\end{array}$ \\
\hline Hidrografia & $\begin{array}{l}\text { Cinco sub-bacias hidrográficas do tipo alongado; Não sujeitas a } \\
\text { enchentes e/ou inundações. }\end{array}$ \\
\hline Biogeografia & $\begin{array}{l}\text { Espécies de peixes, pássaros, bichos ou microrganismos ainda } \\
\text { desconhecidos; Estádios de degradação. }\end{array}$ \\
\hline Unidade Trabalhada pelo Homem & $\begin{array}{l}\text { Extrativismo de madeira; agropecuárias extensivas; Agricultura } \\
\text { de subsistência, comercial e itinerante. }\end{array}$ \\
\hline \multicolumn{2}{|r|}{ Geofácies } \\
\hline Paisagem & $\begin{array}{l}\text { Solo Exposto/Antropizado (SEA), Floresta Primária (FP), } \\
\text { Floresta Secundária (FS) e Cultura Permanente (CP); }\end{array}$ \\
\hline Solo / Relevo & Grupo Barreiras (TQb) e formação Ipixuna (Kix). \\
\hline Clima & Dois subtipos climáticos, sendo o $A f$ e " $A m$ "; \\
\hline Hidrografia & Sub-bacias do rio Ubá, rio Mamorana, rio Moju e rio Acará. \\
\hline Biogeografia & Sub-bacia do rio Acará possui maior área de floresta. \\
\hline Unidade Trabalhada pelo Homem & Ocupação humana e extrativismo animal. \\
\hline \multicolumn{2}{|r|}{ Geótopos } \\
\hline Paisagem & $\begin{array}{l}\text { Rio Acará com } 2.169,72 \mathrm{~km} \text { de extensão; Sub-bacias de formas } \\
\text { elípticas (alongadas); Agricultura do dendê; Colinas com } \\
\text { declives moderados, ou formando morros. }\end{array}$ \\
\hline Solo / Relevo & $\begin{array}{l}\text { Latossolos Amarelo de textura argilosa e média; Relevo plano } \\
\text { e suave ondulado. }\end{array}$ \\
\hline Clima & $A f 2$ e $A f 3$ a precipitação pluviométrica entre 2.489 e $2.851 \mathrm{~mm}$. \\
\hline Hidrografia & $\begin{array}{l}\text { Drenagem com padrão de ramificação de } 3^{\text {a }} \text { a } 5^{\circ} \text { ordem; } \\
\text { Drenagem são regulares; Rede de drenagem com } 22.533,61 \mathrm{~km} \\
\text { de extensão total. }\end{array}$ \\
\hline Biogeografia & $\begin{array}{l}\text { Boas condições físicas de retenção de umidade e boa } \\
\text { permeabilidade. }\end{array}$ \\
\hline Unidade Trabalhada pelo Homem & $\begin{array}{l}\text { Atividades antrópicas que gera alterações, efeitos ou impactos } \\
\text { a montante e a jusante dos rios, provocando desequilíbrio da } \\
\text { paisagem. }\end{array}$ \\
\hline
\end{tabular}

\section{Conclusões}

A metodologia de Bertrand, aplicado ao estudo da paisagem rural da microrregião de ToméAçu, mostrou-se totalmente viável, proporcionando uma análise integrada mosaico de unidades homogêneas com seus elementos em níveis de organização estrutural, que facilitam a compreensão dos processos de evolução e do diálogo geossistêmico desse espaço geográfico, que apresenta paisagens distintas e interações que conferem a essa microrregião uma série de características próprias que vai além da simples soma de seus componentes físicos, biológicos e antrópicos, sendo este último representado pelas perturbações no potencial ecológico e biológico desse espaço rural, a exemplo da produção do agronegócio que forma uma realidade modificada que afeta os geossistemas.

Os mosaicos de unidades homogêneas de paisagem hierarquizada determinam a potencialidade edafoclimáticas deste espaço rural para boa exploração do agronegócio do óleo de palma. Neste sentido, cada mosaico de unidades homogêneas unidade possibilitou compreender a funções dos elementos que compõem as paisagens, bem como compreender a dinâmicas destes elementos e suas inter-relações.

Com a proposta de Bertrand, foi possível compreender os conceitos fundamentais de compartimentação do espaço em zona, domínio, região natural, geossistema, geofácies e geótopo, facilitando ainda a visualização de cenários sistematizados do principal uso e cobertura da terra, recursos hídricos, clima, solo e de relevo, que de maneira inter-relacionados são provedores de recursos naturais.

Em síntese, pode-se considerar que há uma complexa relação entre as unidades hierarquizadas, principalmente quando a paisagem se torna expressão cultural, manifestada através da

Santos, L.S., Nahum, J. S., Santos, C.B., Silva Júnior, O.M. 
utilização de suas potencialidades naturais (bióticos e abióticos).

A percepção geossistêmica betrandiana (1971), permitiu a caracterização e delineamento cartográfico dos mosaicos de unidades homogêneas reconhecível na paisagem rural dessa microrregião, revendo a dinâmica natural indissociável da paisagem e as possíveis implicações (perturbações) decorrentes do seu avanço dendezais sobre nascente e rios da região, pois o dendezeiro é muito exigente em água e pouco tolerante às deficiências hídricas.

A análise das unidades de paisagem sobre o sistema bertrandiano foi um desafio, mas os resultados, mesmo que preliminares, podem auxiliar na indicação de alternativas sustentáveis de exploração de aquíferos, bem como na adoção de um plano conservacionista do solo, da água, do balanço e troca de energia entre a superfície e a atmosfera, bem como da biodiversidade.

Os perfis (horizontal e vertical das zonas homogêneas) do uso e cobertura da terra, da climatologia, do solo, do relevo e principalmente hidrológico, representado pelo conjunto das terras drenadas de variáveis, de tamanhos e de densidades distintas.

O caráter geossistêmico, não só apresenta a potencialidades das unidades de paisagem em níveis, como, também representa a uma espécie de cartografia complexa, raramente isolados, pois que sofreram intensas intervenções humanas ao longo do tempo, despontando o grau de responsabilidades daqueles que projetam de forma indiscriminada $\mathrm{e}$ sem critério, alargar as áreas de cultivos nessa microrregião.

Deste modo, a análise sistêmica a partir de suas formas espaciais do presente, testemunha-se do passado que ainda persiste na microrregião de Tomé-Açu, a exemplo as áreas degradadas, que agora servem de espaço para expansão da produção do dendê.

Contudo deve-se evitar a destruição do meio ambiente, tornando-o mais instável à medida que os equilíbrios naturais são substituídos pelos equilíbrios secundários, diretamente ligados à forma e ao ritmo das explorações dessa oleaginosa.

\section{Agradecimentos}

Os autores agradecem a coordenação, ao corpo docente e funcionários do Programa de PósGraduação em Geografia (PPGeo) do Instituto de Filosofia e Ciências Humanas (IFCH), da Universidade Federal do Pará (UFPA), que não mediram esforços para promover um excelente ambiente acadêmico de trabalho e pesquisa. Ao
Laboratório de Sensoriamento Remoto e Geoprocessamento da Universidade Federal do Pará (LAIGI/UFPA).

\section{Referências}

Ab'sáber, A. N., 2003. Os domínios de natureza no Brasil: potencialidades paisagísticas. Ateliê Editorial.

Almeida, C. A., Coutinho, J. A. M., Esquerdo, J. C. D. Adami, A., Venturieri, A., Diniz, C. G., Dessay, N., Durieux, L., Gomes, A. R., 2014. Status and prospects of oil palm in the Brazilian Amazon. Biomass and bioenergy, v. 67, p. 270278. Disponível em: https://doi.org/10.1016/j.biombioe.2014.05.00 5. Acesso em: 21 jul. 2019.

Alves, E. J. C., Rêgo, J. C., Galvão, C. D. O., Vieira, J. B. D. A., 2018. Limits and conditions for the exploitation of alluvial aquifers in the Brazilian semi-arid region. RBRH, v. 23, 2018. Disponível em: http://dx.doi.org/10.1590/23180331.0318160049. Acesso em: $21 \mathrm{dez} .2018$.

Aparecido, L. E. D. O., Rolim, G. D. S., Richetti, J., Souza, P. S. D., Johann, J. A., 2016. Köppen, Thornthwaite and Camargo climate classifications for climatic zoning in the State of Paraná, Brazil. Ciência e Agrotecnologia, v. 40, n. 4, p. 405-417.

Araújo, M. J., 2000. Fundamentos de agronegócios. Editora Atlas AS.

Barcelos, E., Pacheco, A. R., Müller, A. A., Viegas, I., Tinoco, P. B., 1987. Dendê: informações básicas para seu cultivo. Embrapa Amazônia Oriental-Documentos (INFOTECAE).

Becker, B. K., 1995. A (des) ordem global, o desenvolvimento sustentável e a Amazônia. vários autores, Geografia e Meio Ambiente no Brasil, Hucitec, São Paulo.

Becker, B., 2009. Amazônia: geopolítica na virada do III milênio. Rio de Janeiro: Garamond. 168p.

Benda, F., Alves, M., Corrêa, F., 2017. Estudo do Risco de Degradação por Assoreamento dos Corpos d'água Superficiais Utilizando SIG. Informática Pública, 9(2), 55-69.

Bertrand, G., Bertrand, C., 2007. Uma geografia transversal e de travessias: o meio ambiente através dos territórios e das temporalidades. Maringá: Massoni, p. 290-291.

Bolfe, É. L., Batistella, M., 2012. Análise florística e estrutural de sistemas silviagrícolas em ToméAçu, Pará. Pesquisa Agropecuária Brasileira, 46(10), 1139-1147. 
Cardoso, F. H. M., 1977. Amazônia: expansão do capitalismo. Editora brasiliense, São Paulo Brasil.

Costa, F. A., 2012. Formação rural extrativista na Amazônia: os desafios do desenvolvimento capitalista (1720-1970). Belém: NAEA. (Coleção Economia Política da Amazônia. Série III - Formação histórica, v. 1).

Cunha, S. B., Guerra, A J., 2011. Geomorfologia e meio ambiente. Organizadores. $-10^{\mathrm{a}}$ Ed. - Rio de Janeiro: Bertrand Brasil.

Da Silva Gemaque, A. M., Beltrão, N. E. S., Mesquita, M. D. O. B., Ferreira Filho, H. R., 2017. Qualidade de Vida do Agricultor Familiar e sua Relação com a Dendeicultura: Estudo de uma Comunidade Rural no Município De Moju, Pa. Revista Brasileira de Gestão e Desenvolvimento Regional, v. 13, n. 1.

Da Silva, T. M., Dos Santos, B. P., 2010. Sistemas de drenagem e evolução da paisagem. Revista Geográfica Acadêmica, 4(1), 5-19.

De Britto, M. C., Ferreira, C. C. M., 2011. Paisagem e as diferentes abordagens geográficas. Revista de Geografia-PPGEOUFJF, v. 1, n. 2.

De Carli, A. A., 2015. Água é vida: eu cuido, eu poupo: para um futuro sem crise. Editora FGV.

De Carvalho, A. C. A., Nascimento, E. N., Nahum, J. S. A., 2014. Dendeicultura e a sua Expansão no Estado do Pará: Uma Interpretação Geográfica do Evento. Anais do VI Congresso Ibero Americano de Estudios Territoriales y Ambientales.

Ferraro. L. M. W, Bered. A. R., Pagel. S. M., 2012. A Unidade de paisagem Natural como Base Especial para Gestão Ambiental. Paisagem: leituras, significados transformações. (Org.) ROBERTO, Verdum... [et al.]. Porto Alegre: Editora da UFRGS. p. 37 - 47.

Ferreira, A. B., 2001. Alcoforado, M. J., Vieira, G. T., Mora, C., Jansen, J. Metodologias de análise e de classificação das paisagens. $\mathrm{O}$ exemplo do projecto Estrela. Finisterra, 36(72). Disponível em: https://doi.org/10.18055/Finis1632. Acesso em: 05 mai. 2019.

Ferreira, M. J. M., Viana Júnior, M. M., Pontes, A. G. V., Rigotto, R. M., Gadelha, D., 2016. Gestão e uso dos recursos hídricos e a expansão do agronegócio: água para quê e para quem? Ciência \& Saúde Coletiva, v. 21, p. 743-752, $2016 . \quad$ Disponível em: http://dx.doi.org/10.1590/141381232015213.21012015. Acesso em: $22 \mathrm{fev}$. 2019.

Furlan Júnior, J., Kaltner, F.J., Azevedo, G.F.P., 2006. Biodiesel: Porque tem que ser dendê.
Belém: Embrapa Amazônia Oriental, Palmasa. 205 p.

Girão, O., Correa, A. D. B. 2004. A contribuição da geomorfologia para o planejamento da ocupação de novas áreas. Revista de Geografia, Recife, 21(2), 36-58.

Glass, V., 2013. Expansão do dendê na Amazônia brasileira: elementos para uma análise dos impactos sobre a agricultura familiar no nordeste do Pará. Repórter Brasil. Fases: São Paulo, sd, 15p.

INMET. Instituto Nacional de Meteorologia, 2009. Normais Climatológicas do Brasil 1961-1990. Versão revista e ampliada Instituto Nacional de Meteorologia.

Kaltner, F. J., Furlan Júnior, J., Da Silva, E. B., Veiga, A. S., Vaz, J. D. C., 2004. Viabilidade técnica e econômica de produção de ésteres de óleo de palma, para utilização como substituto de óleo diesel, na Amazônia. Embrapa Amazônia Oriental-Documentos (INFOTECAE),

Ker, J. C., 1997. Latossolos do Brasil: uma revisão. Revista Geonomos, 5(1).

Lago, A., Pádua, J. A, 2017. O que é ecologia. Brasiliense.

Lopes, A. P., 2015. Território usado e recursos hídricos: o uso da água na produção de flores e plantas ornamentais em Holambra-SP. 2015. 164 f. Dissertação (Mestrado) - Universidade Estadual Paulista, Instituto de Geociências e Ciências Exatas.

Lumbreras, J. F., Naime, U. J., Carvalho Filho, A. D., Wittern, K. P., Shinzato, E., Dantas, M. E., Pimentel, J., 2003. Zoneamento agroecológico do Estado do Rio de Janeiro / José Francisco Lumbreras... [et al.]. - Rio de Janeiro: Embrapa Solos. 113 p. - (Embrapa Solos. Boletim de Pesquisa e Desenvolvimento, n. 33.

Martinelli, M., Pedrotti, F., 2011. A cartografia da unidade de paisagem: questões metodológicas. Revista do Departamento de Geografia, 14, 39. 46.

Martorano, L. G., Nechet, D., Pereira, L. C., 1993. Tipologia climática do Estado do Pará: adaptação do método de Köppen. Boletim de Geografia Teorética, v. 23, p. 45-46.

Miranda, E. E. De, (Coord.), 2005. Brasil em Relevo. Campinas: Embrapa Monitoramento por Satélite.

Miranda, E. E. De, (Coord.)., 2005. Brasil em Relevo. Campinas: Embrapa Monitoramento por Satélite.

Monteiro, R. H. Rocha, C. A. Quanto de Uma Paisagem Pode Entrar em Um Olho. Anais do 
VI Seminário Nacional de Pesquisa em Arte e Cultura Visual Goiânia-GO: UFG, FAV, 2013.

Müller, A. A., Alves R. M., 1997. A dendeicultura na Amazônia brasileira Embrapa Amazônia Oriental-Documentos (INFOTECA-E), 1997.

Müller, A. A., Furlan Júnior, J., Celestino Filho, P. A., 2006. Embrapa Amazônia Oriental e o agronegócio do dendê no Pará. Embrapa Amazônia Oriental-Documentos (INFOTECAE).

Pissinati, M. C., Archela, R. S., 2009. Geossistema território e paisagem-método de estudo da paisagem rural sob a ótica bertrandiana. Geografia, v. 18, n. 1, p. 5-31.

Puntel, G. A., 2012. Paisagem e a Geografia. Paisagem: Leitura, Significado e transformações/ [Organizado por] Verdum, R., Vieira, L., Pinto, B.F. e da Silva, L.A. Porto Alegre. Editora da UFRGS. 256p.: il., 16 x 23 $\mathrm{cm}$.

Ramalho Filho, A., Da Motta, P., Freitas, P., Teixeira, W., 2010. Zoneamento agroecológico, produção e manejo para a cultura da palma de óleo na Amazônia. Rio de Janeiro: Embrapa Solos.

Ribeiro, L. S., Da Gloria Alves, M., 2008. Análise de suscetibilidade à erosão laminar no município de Campos dos Goytacazes/RJ através de técnicas de geoprocessamento. Estudos Geográficos: Revista Eletrônica de Geografia, v. 6, n. 1, p. 89-100.

Rodrigues, T. E., Dos Santos, P. L., Rollim, P. A. M., Santos, E., Rego, R. S., Da Silva, J. M. L., Gama, J. R. N., 2001. Caracterização e classificação dos solos do Município de ToméAçu, PA. Embrapa Amazônia OrientalDocumentos (INFOTECA-E).

Sauer, C. O., 2004. A Morfologia da Paisagem. Paisagem, tempo e cultura / Organização Roberto Lobato Corrêa, Zeny Rosendahl. 2 Ed. - Rio de Janeiro: EdUERJ.

Schier, R. A., 2003. Trajetórias do conceito de paisagem na geografia. Raega-O Espaço Geográfico em Análise, v. 7. Disponível em: http://dx.doi.org/10.5380/raega.v7i0.3353. Acesso em: 15 mai. 2019.

Souza, R. J., 2009. O sistema GTP (geossistematerritório-paisagem) como novo projeto geográfico para a análise da interface sociedade-natureza. Revista Formação, n. 16, p. 89-106.

Suertegaray. D. M., Guasselli, L., 2004. Paisagens (Imagens e Representações) do Rio Grande do Sul. In VERDUM, R., BASSO, L. A. SUERTEGARAY. D. M. (Org.). Rio Grande do
Sul: Paisagem Território em Transformação. Porto Alegre: Editora UFRGS.

Thomaz Júnior, A., 2010. O agrohidronegócio no centro das disputas territoriais e de classe no Brasil do século XXI. Campo-território Revista de geografia agrária, v. 5, n. 10, 2010.

Vasconcelos, T. C. C. D., 2013. Análise dos Índices de Erosividade a partir de dados de precipitação de postos pluviométricos do Município de João Pessoa-PB. Trabalho de conclusão de curso em Geociências. João Pessoa, PB.

Veiga, A. M., Trindade, M. C., Souza, R. M., Oliveira, W. N., 2013. Caracterização Hidromorfológicas da Bacia Hidrográfica do Rio dos Bois. Anais do XX Simpósio Brasileiro de Recursos Hídricos.

Verdum, R., Dos Santos Vieira, L. D. F., Pinto, B. F., Da Silva, L. A. P. (Eds.), 2012. Paisagem: leituras, significados transformações. Editora da UFRGS.

Villela, S. M., Mattos, A., 1975. Hidrologia aplicada. In Hidrologia aplicada. McGraw-Hill.

Vitte, A. C., 2005. O Uso da Morfometria de Bacias de Drenagem como Suporte ao Mapeamento da Fragilidade Ambiental nos Municípios de Sumaré e Valinhos, Região Metropolitana de Campinas (SP), Brasil. Anais do $\mathrm{X}$ Encontro de Geógrafos da América Latina. Universidade de São Paulo.

Watrin, O. D. S., Santos, D., Valente, M., 2011. Base de dados geográficos como subsídio à gestão territorial na fazenda experimental da Embrapa Amazônia Oriental, Belém, PA. Embrapa Amazônia Oriental-Boletim de Pesquisa e Desenvolvimento (INFOTECA-E).

Whately, M., Campanili, M., 2016. O século da escassez: Uma nova cultura de cuidado com a Água: Impasses e Desafios. Editora Schwarcz Companhia das Letras.

Zacharias, A. A., 2010. A representação gráfica das unidades de paisagem no zoneamento ambiental São Paulo: Ed. UNESP. 